\title{
Behavior and Bio-Interactions of Anthropogenic Particles in Marine Environment for a More Realistic Ecological Risk Assessment
}

OPEN ACCESS

Edited by: Antonia Praetorius, University of Amsterdam, Netherlands

Reviewed by:

Julian Gallego Urrea, University of Gothenburg, Sweden Huacheng Xu, Nanjing Institute of Geography and Limnology (CAS), China

${ }^{*}$ Correspondence: Ilaria Corsi ilaria.corsi@unisi.it

Specialty section: This article was submitted to Biogeochemical Dynamics, a section of the journa Frontiers in Environmental Science

Received: 07 January 2020 Accepted: 28 April 2020

Published: 11 June 2020

Citation:

Corsi I, Bergami E and Grassi G (2020) Behavior and Bio-Interactions of Anthropogenic Particles in Marine Environment for a More Realistic Ecological Risk Assessment. Front. Environ. Sci. 8:60 doi: 10.3389/fenvs.2020.00060

\author{
Ilaria Corsi*, Elisa Bergami and Giacomo Grassi \\ Department of Physical, Earth and Environmental Sciences, University of Siena, Siena, Italy
}

Owing to production, usage, and disposal of nano-enabled products as well as fragmentation of bulk materials, anthropogenic nanoscale particles (NPs) can enter the natural environment and through different compartments (air, soil, and water) end up into the sea. With the continuous increase in production and associated emissions and discharges, they can reach concentrations able to exceed toxicity thresholds for living species inhabiting marine coastal areas. Behavior and fate of NPs in marine waters are driven by transformation processes occurring as a function of NP intrinsic and extrinsic properties in the receiving seawaters. All those aspects have been overlooked in ecological risk assessment. This review critically reports ecotoxicity studies in which size distribution, surface charges and bio-nano interactions have been considered for a more realistic risk assessment of NPs in marine environment. Two emerging and relevant NPs, the metal-based titanium dioxide $\left(\mathrm{TiO}_{2}\right)$, and polystyrene (PS), a proxy for nanoplastics, are reviewed, and their impact on marine biota (from planktonic species to invertebrates and fish) is discussed as a function of particle size and surface charges (negative vs. positive), which affect their behavior and interaction with the biological material. Uptake of NPs is related to their nanoscale size; however, in vivo studies clearly demonstrated that transformation (agglomerates/aggregates) occurring in both artificial and natural seawater drive to different exposure routes and biological responses at cellular and organism level. Adsorption of single particles or agglomerates onto the body surface or their internalization in feces can impair motility and affect sinking or floating behavior with consequences on populations and ecological function. Particle complex dynamics in natural seawater is almost unknown, although it determines the effective exposure scenarios. Based on the latest predicted environmental concentrations for $\mathrm{TiO}_{2}$ and PS NPs in the marine environment, current knowledge gaps and future research challenges encompass the comprehensive study of bio-nano interactions. As such, the analysis of NP biomolecular coronas can enable a better assessment of particle uptake and related cellular pathways leading to toxic effects. Moreover, the formation of an environmentally derived corona (i.e., eco-corona) in seawater accounts for NP physical-chemical alterations, rebounding on interaction with living organisms and toxicity.

Keywords: anthropogenic particles, marine environment, ecological risk assessment, polystyrene, titanium dioxide, behavior, eco-corona, biomolecular corona 


\section{INTRODUCTION}

Engineered nanoscale materials (NMs) and particles (NPs) are used extensively in a wide range of emerging technologies and commercial applications including biomedicine, pharmaceuticals and personal care products, renewable energy, and electronic devices ( $\mathrm{Nel}$ et al., 2006). According to EU recommendations, a nanomaterial is defined as "a material with one or more dimensions in the size range $1-100 \mathrm{~nm}$ " (European Commission [EU], 2011). Another commonly agreed definition is "any organic, inorganic, or organometallic materials presenting specific chemical, physical, and/or electrical properties that vary as a function of the size and shape of the material" (Hochella et al., 2019).

Owing to production, usage, and disposal of nanoenabled products as well as fragmentation of bulk materials, anthropogenic NPs can enter the natural environment, and through different compartments (air, soil, and water), end up into the sea (Corsi et al., 2014). With the continuous increase in production and associated emissions and discharges as well as due to weathering processes occurring during various stages of the product life cycle, they can reach concentrations able to exceed toxicity thresholds for living species inhabiting marine coastal areas (Garner et al., 2017; Lebreton and Andrady, 2019). Modeled predicted environmental concentrations (PECs) of the most common inorganic and organic engineered NMs in surface waters, based on production, usage, disposal, and fragmentation, have been estimated in the range of $<15 \mu \mathrm{g} \mathrm{L}^{-1}$ for nanoplastics, around $\mu \mathrm{g} \mathrm{L}^{-1}$ for titanium dioxide $\left(\mathrm{TiO}_{2}\right)$ and zinc oxide $(\mathrm{ZnO}) \mathrm{NPs}$, and $\mathrm{ng} \mathrm{L}^{-1}$ for silver ( $\mathrm{Ag}$ ) NPs, fullerenes, carbon nanotubes (CNTs), and cerium oxide $\left(\mathrm{CeO}_{2}\right)$ (Gottschalk et al., 2013; Sun et al., 2014; Lenz et al., 2016; Renner et al., 2018). PECs are likely to increase in the near future due to the growing production and commercial applications of nanoenabled products and fragmentation of larger particles already present in the environment as for instance for nanoplastics (Andrady, 2017).

Particles reaching the sea may substantially differ in size as well as in physical chemical properties from primary particles incorporated in commercial products (Lowry et al., 2012; Mitrano et al., 2015; Nowack and Mitrano, 2018). During synthesis, attributes as chemical composition, size, geometry, crystallinity, porosity, roughness, hydrophobicity/hydrophilicity and surface coating are tightly controlled, resulting in small particles having unique chemical and physical properties. They reach the sea following the same routes of legacy and emerging chemical pollutants through domestic and industrial discharges and mismanaged waste disposal from which they ultimately are transported to wastewater treatment plants (WWTPs) and released in sewage effluents (Baalousha et al., 2016; Garner et al., 2017; Choi et al., 2018). Once reaching sea water, being rarely homogeneous, they interact with high amounts of ionic species (released by mineral salts) and inorganic and organic colloidal particles [i.e., iron oxides and natural organic matter (NOM)], which affect their fate and behavior (Keller et al., 2010; Petosa et al., 2010; von der Kammer et al., 2012; Praetorius et al., 2014).
Both heteroaggregation (i.e., the aggregation between nonhomologous particles) and homoaggregation (i.e., aggregation of NPs among themselves) represent important processes (Praetorius et al., 2020) that will occur in the presence of relatively high $\mathrm{pH}(8)$ and ionic strength such as in sea water [mainly due to chloride $\left(\mathrm{Cl}^{-}\right)$, sodium $\left(\mathrm{Na}^{+}\right)$, sulfate $\left(\mathrm{SO}^{2-}\right)$, magnesium $\left(\mathrm{Mg}^{2+}\right)$, calcium $\left(\mathrm{Ca}^{2+}\right)$, and potassium $\left.\left(\mathrm{K}^{+}\right)\right]$ (Therezien et al., 2014).

Biopolymers produced by marine phytoplankton, known as exopolymeric substances (EPS), can influence aggregation and transformation of NPs in aqueous media. Indeed, they can be present as dissolved organic matter (DOM) or as colloidal particles [particulate organic matter (POM)], namely, transparent exopolymer substances (TEP) (Long and Azam, 1996; Passow, 2002; Mari et al., 2017). Furthermore, NPs can promote the transition of such DOM molecules into suspended particles, thereby altering the DOM-POM balance of organic matter in seawater (Chen et al., 2011; Shiu et al., 2019). EPS can change their assembly kinetics in the presence of NPs, following both hydrophobic and electrostatic interactions, ultimately functioning as nucleation sites for phytoplanktonic exudates (Chen et al., 2011; Adeleye and Keller, 2014; Adeleye et al., 2014; Kadar et al., 2014). Given the abundance of natural colloids in coastal and oceanic waters, it is expected that heteroaggregation outclasses the contribution of homoaggregation in determining NP aquatic behavior and environmental fate. NP interplay with ubiquitous organic and inorganic colloids takes shape in highly complex heteroaggregation processes, whose outcomes were exhaustively delineated by Praetorius et al. (2020). In particular, the behavior of natural colloids will be more relevant in determining the expected environmental fate of NP in heteroaggregates than previsions based solely on homoaggregation processes. In this regard, different heteroaggregation pathways can be envisaged, starting with NP-colloid dimer formation and evolving toward more complex arrangements. Ultimately, however, natural colloid-attached NPs will generally follow the transport dictated by the larger suspended particulate matter, postulating consequences for interactions with living entities and ecotoxicity.

Differently, interaction of NPs with dissolved biomolecules can, in certain conditions, lead natural organic matter (NOM) into the formation of a nanoscale coating analogous to protein corona in mammalian systems, potentially affecting aggregation/deposition and transport of the NPs in fluids, but more importantly uptake and toxicity to marine species (Lundqvist et al., 2008; Monopoli et al., 2011). Such new extrinsic properties related to the formation of a protein corona may affect consistently the biological activity of NPs in terms of biodistribution, cellular uptake (biokinetics), and ultimate toxicity (Marques-Santos et al., 2018; Grassi et al., 2019).

Overall, a deeper understanding of NP eco-interactions is crucial for predicting their fate and ecotoxicity. Owing to the complexity in predicting and modeling NP properties and interactions in natural seawater (NSW), ecotoxicity could be a valuable tool for both screening and categorizing NPs for risk assessment purposes. On the other hand, more realistic 
exposure studies and the formulation of ad hoc guidance protocols are required for a proper ecological risk assessment of nanoscale particles (Corsi et al., 2014, 2018; Petersen et al., 2015; Holden et al., 2016).

The lack of suitable analytical methods for a fast and cost-efficient detection of anthropogenic particles in aquatic matrices is one of the major constraints for the comprehensive understanding of the biogeochemistry of anthropogenic NPs, such as $\mathrm{TiO}_{2}$ and PS NPs (da Silva et al., 2011; Huvet et al., 2016; Schwaferts et al., 2019).

In order to understand the potential effects and toxicity mechanisms of these anthropogenic NPs to the marine biota and provide methodologies for environmental risk assessment purposes, several ecotoxicity studies have focused on acute exposures of marine model organisms at the base of the food webs, ranging from phytoplankton and zooplankton to benthic filter feeders. Most of the studies reported are representative of worst-case scenarios in coastal areas, where these anthropogenic NPs have been predicted to reach high concentrations (TovarSánchez et al., 2013; Labille et al., 2020).

This review critically reports ecotoxicity studies in which size distribution, surface charges, and bio-nano interactions have been considered for a more realistic risk assessment of anthropogenic NPs in marine environment. Two emerging and relevant NPs, the metal-based $\mathrm{TiO}_{2}$ and polystyrene (PS) as a proxy for nanoplastics, are reviewed, and their impact on marine biota (from planktonic species to invertebrates and fish) is discussed as a function of particle size and surface charges (negative vs. positive), which affect their behavior and interaction with the biological material.

\section{$\mathrm{TiO}_{2}$ AND PS NANOPARTICLE PROPERTIES}

Titanium dioxide NPs have been largely included in several commercial products (industrial, pharmaceutical, and food) due to their brightness, high refractive index, and UV resistance (Vance et al., 2015). Their photoelectronical properties allow solar energy conversion and photocatalytic chemical degradation piloting specific nanotechnological application as for instance in solar cells and in water and wastewater treatment including disinfection due to the generation of reactive species upon UV irradiation (390 nm) (Carp et al., 2004; Chong et al., 2010). Upon photoexcitation, nanoscale $\mathrm{TiO}_{2}$ produces an electronhole pair that may migrate to the particle surface where it is involved in surface oxidation reactions or remove an electron from hydroxide, producing the hydroxyl radical. Such photochemical properties rebound on their safety once reaching the natural environment both from direct application (e.g., water purification) or indirectly once released from commercial products (e.g., sunscreen, paints, and textiles) (Robichaud et al., 2009; Botta et al., 2011; Windler et al., 2012). Anionic species, mainly carbonate and chloride, naturally occurring in seawater media, have been shown to significantly reduce $\mathrm{TiO}_{2}$ NP photoreactivity and increase aggregation, thus, having a strongest role in suppressing hydroxyl radical generation by substituting hydroxyl ions. Haynes et al. (2017) recently reviewed photocatalytic effects of $\mathrm{TiO}_{2}$ NPs on aquatic species underlining how important it is to define environmental relevant factors in water media able to affect NP physico-chemical properties and, therefore, behavior and effects.

Polymeric-based NPs, such as PS NPs, may enter the environment both from primary sources, when present as newly synthesized nano-polymers, which are not retained by WWTPs (Blair et al., 2017), and secondary sources, as nanoscale polymers derived from the degradation of mismanaged products (Lambert et al., 2013; Andrady, 2017). Polymeric NPs have been used in several nanotechnology applications, ranging from biosensors and photonics (Velev and Kaler, 1999) to cosmetics (Guterres et al., 2007; Leslie, 2014; Hernandez et al., 2017), food nanocomposites (Silvestre et al., 2011; Hernandez et al., 2019), and drug nanocarriers (Jiménez-Fernández et al., 2014). In nanomedicine, many in vitro studies in human cell lines have been carried out using functionalized PS NPs to provide insights into the specific mechanisms of cell recognition, signaling cascade, and pathways of toxicity (e.g., Johnston et al., 2010; Bexiga et al., 2011; Liu et al., 2011; Salvati et al., 2011; Fröhlich et al., 2012; Wang et al., 2013; Loos et al., 2014). The most common PS NPs are carboxylate (PS-COOH) and amino-modified ( $\mathrm{PS}-\mathrm{NH}_{2}$ ), corresponding to a negative and positive surface, charge respectively, usually associated to peculiar cellular pathways (Bexiga et al., 2011, 2014; Salvati et al., 2011; Wang et al., 2013).

From a wider environmental perspective, potential emissions of PS NPs are also associated with the slow and inevitable breakdown of large PS-based products once released in the marine environment, due to mechanical processes (Zhang et al., 2012; Kuo et al., 2014), weathering agents (e.g., UV radiation and high temperature) (Lambert and Wagner, 2016), and biota (Davidson, 2012).

An overwhelming part of the scientific research has been dedicated to the study of the occurrence, distribution, transformation, and impacts of marine litter. The continuous degradation of plastic debris in the water column, down to the nano-fraction, has been at first hypothesized (Cózar et al., 2014) and then confirmed by laboratory (Zhang et al., 2012; Gigault et al., 2016; Lambert and Wagner, 2016; Hernandez et al., 2019; Zhu et al., 2020) and in situ studies (Ter Halle et al., 2017; Schirinzi et al., 2019), raising concerns due to the potential harm to the marine biota associated to the lower plastic size (as reviewed by Chae and An, 2017). In this context, the term nanoplastics usually refers to polymers with various colors and shapes (e.g., fiber, film, spherule, and fragment), and sizes below $1 \mu \mathrm{m}$, thus, comprehensive of the sub-micron and nanometric fraction (Hartmann et al., 2019).

\section{NP FATE AND BEHAVIOR IN SEA WATER}

Owing to their growing production and continuous inflow into the environment (Gottschalk and Nowack, 2011; Garner et al., 2017), anthropogenic NPs such as $\mathrm{TiO}_{2}$ and PS NPs are likely to be incorporated in natural biogeochemical cycles, though 
it is difficult to determine their exact contribution alongside naturally occurring NPs. Once in the marine environment, anthropogenic NPs should not be conceived as single entities, but as a dynamic system of particles interacting with the surrounding ionic species and other colloids. To address these features, several heteroaggregation studies have investigated the individual role of monovalent $(\mathrm{NaCl})$ and divalent salts $\left(\mathrm{MgCl}_{2}, \mathrm{CaCl}_{2}\right)$ and their valences on NP behavior and stability as well as NOM model compounds such as fulvic acid (FA), tannic acid (TA), and humic acid (HA) in simplified systems (Romanello and Fidalgo de Cortalezzi, 2013; Cai et al., 2018; Danielsson et al., 2018; Singh et al., 2019).

In order to describe these complex interactions, the Derjaguin-Landau-Verwey-Overbeek (DLVO) theory is commonly applied (Romanello and Fidalgo de Cortalezzi, 2013; Cai et al., 2018), although it is restrictive to the balance between electrostatic and van der Waals forces. Several extensions of the DLVO theory have also been proposed to model inter-NP interactions in suspensions, for example, considering surface roughness, hydration forces, and steric effects (Wu et al., 1999; Walsh et al., 2012; Cardellini et al., 2019; Praetorius et al., 2020).

As a result of the NP intrinsic (e.g., size, shape, roughness, and crystallinity) and extrinsic (e.g., temperature, ionic strength and composition, NOM) properties (Petosa et al., 2010; Baalousha, 2017), NPs may undergo rapid transformations in NSW, which drive NP fate and determine the presence (or absence) of effects on the marine biota (Matranga and Corsi, 2012; Corsi et al., 2014; Blasco et al., 2015).

In order to ascertain NP features in natural exposure media, light scattering [i.e., dynamic light scattering (DLS)] and electrophoretic mobility (EM) analyses are among the most common techniques employed, providing information about NP hydrodynamic size, agglomeration kinetics, and surface charge (da Silva et al., 2011; Ribeiro et al., 2017; Cai et al., 2018; Mourdikoudis et al., 2018). The measurement of $\zeta$-potential (mV) by EM can be used as an indicator of the NP surface charge and, thus, colloidal stability in the medium, with low absolute values usually associated with the screening of NP surface charge (Mourdikoudis et al., 2018). DLS and EM techniques are usually coupled with scanning or transmission electron microscopy (SEM/TEM), which allow to display the agglomeration state of colloidal suspensions and also the specific interactions occurring at the biological surfaces, such as bacteria (Gupta et al., 2016; Fu et al., 2018), microalgae (e.g., Chen et al., 2011; Wang et al., 2016; Bergami et al., 2017; González-Fernández et al., 2019; Seoane et al., 2019), and invertebrate cells (e.g., Canesi et al., 2016a,b; Ciacci et al., 2019). The limit of these techniques is the high concentration of the sample required (usually in the range of $\mu \mathrm{g}$ $\mathrm{ml}^{-1}$ ) (Ribeiro et al., 2017), which often do not reflect PECs for the anthropogenic NPs, in the range of $\mu \mathrm{g} \mathrm{L}^{-1}$ for $\mathrm{TiO}_{2} \mathrm{NPs}$ and ng $\mathrm{L}^{-1}$ for PS NPs (da Silva et al., 2011; Gottschalk et al., 2013).

\section{$\mathrm{TiO}_{2} \mathrm{NP}$ Behavior in Seawater Media}

One of the most common $\mathrm{TiO}_{2}$ NPs tested in ecotoxicity studies is the P25 powder, characterized by a spheroid irregular structure, mostly containing anatase and with a primary size of $24 \pm 7 \mathrm{~nm}$ (Brunelli et al., 2013; Della Torre et al., 2015b). Under controlled laboratory conditions, $\mathrm{TiO}_{2}$ stock suspensions are extensively sonicated prior to use to ensure a good dispersion in the exposure media, as described by Brunelli et al. (2013). Once in NSW, $\mathrm{TiO}_{2}$ NPs have been shown to quickly agglomerate, reaching micrometric sizes and wide size distribution within the first minutes after the preparation of the colloidal suspensions (Della Torre et al., 2015b; Hu et al., 2018; Ciacci et al., 2019). The same behavior has been observed in standard marine algal culture (F/2) medium, characterized by high salt content (Morelli et al., 2018). In solutions with high ionic strength, divalent cations $\left(\mathrm{Ca}^{2+}\right.$ and $\mathrm{Mg}^{2+}$ ) have a major role in $\mathrm{TiO}_{2}$ aggregation, since they can adsorb onto NP surfaces, neutralizing the negative charge at $\mathrm{pH}$ values greater than the point of zero charge (French et al., 2009; Romanello and Fidalgo de Cortalezzi, 2013). On the contrary, $\mathrm{TiO}_{2}$ nanoscale aggregates have been found soon after dispersion in media characterized by lower ionic strength, such as freshwater (Sillanpää et al., 2011), and absence of NOM, such as phosphatebuffered saline (PBS) (Grimaldi et al., 2013) and artificial sea water (ASW) (Brunelli et al., 2013). Both the agglomerate size and rate in NSW have been found to increase with $\mathrm{TiO}_{2} \mathrm{NP}$ concentration, due to the enhanced collision among NPs (Hu et al., 2018). The surface of $\mathrm{TiO}_{2} \mathrm{NPs}$ is dominated by three groups (i.e., $\mathrm{TiO}^{-4 / 3}, \mathrm{TiO}_{2}{ }^{-2 / 3}$, and $\mathrm{TiO}_{3}$ ) (Bourikas et al., 2001), displaying a point of zero charge at $\mathrm{pH} 6-8$, depending on the electrolytes present in solution (Romanello and Fidalgo de Cortalezzi, 2013). In natural marine waters, $\mathrm{TiO}_{2}$ NPs usually display a negative surface charge, which is strongly reduced (in absolute values) in NSW, due to the ionic strength-induced compression of NP electrical double layer (Brunelli et al., 2013; Romanello and Fidalgo de Cortalezzi, 2013; Morelli et al., 2018). Owing to their strong agglomeration behavior, $\mathrm{TiO}_{2}$ NPs have been shown to settle in NSW in a concentration-dependent manner, with the removal of $50 \%$ up to $80 \%$ of the suspended NPs over $6 \mathrm{~h}$ observed at 10 and $50 \mu \mathrm{g} \mathrm{ml}^{-1}$, respectively (Della Torre et al., 2015b). Doyle et al. (2015) observed that up to $97 \pm 5.1 \%$ of $\mathrm{TiO}_{2}$ NPs were present as heteroaggregates in NSW incorporated in the marine snow, with enhancing settling rates over 72 h. Similarly, Morelli et al. (2018) reported an initial constant sedimentation rate of $\mathrm{TiO}_{2} \mathrm{NPs}$ in the $\mathrm{F} / 2$ medium, with $58 \%$ of $\mathrm{TiO}_{2}$ settling at $6 \mathrm{~h}$ after dispersion, followed by a $92 \%$ removal reached at $24 \mathrm{~h}$. Although some nanoscale $\mathrm{TiO}_{2}$ aggregates $(200 \mathrm{~nm})$ may still remain in suspension, as shown by DLS analysis of $\mathrm{TiO}_{2}$ NPs at $1 \mu \mathrm{g} \mathrm{ml}^{-1}$ after $24 \mathrm{~h}$ in NSW from the Adriatic Sea (Ciacci et al., 2019), the complete sedimentation of $\mathrm{TiO}_{2}$ NPs can be reached after $50 \mathrm{~h}$, regardless of the presence of NOM (Brunelli et al., 2013) or trace metals such as cadmium at $100 \mu \mathrm{g} \mathrm{L}^{-1}$ (Della Torre et al., 2015b), indicating that high ionic strength (i.e., salinity from $35 \%$ to $41 \% 0$ ) mainly determines the behavior of $\mathrm{TiO}_{2} \mathrm{NPs}$ in the marine environment. On the opposite, $\mathrm{TiO}_{2}$ suspensions in ultrapure water appear to be stable over time (6 h) (Della Torre et al., 2015b).

Several studies have explored the effect of NOM on $\mathrm{TiO}_{2}$ stability and behavior in aquatic environments to correlate NOM-NP interactions to the toxicity observed in aquatic species (reviewed in Grillo et al., 2015). However, quantitative predictions are difficult due to the heterogeneity and variability of colloidal interactions, which are usually assessed in 
simple systems with single ionic species and/or NOM analogs (Praetorius et al., 2020). NOM model compounds, such as FA, TA, and HA, generally exert a stabilizing effect of $\mathrm{TiO}_{2}$ suspensions via adsorption or hydrophobic interactions, with an increase in NP $\zeta$-potential toward more negative values (Romanello and Fidalgo de Cortalezzi, 2013; Mwaanga et al., 2014; Danielsson et al., 2018). For example, in the case of Suwannee River FA, functional carboxylic and phenolic groups may interact with $\mathrm{TiO}_{2}$ (anatase) active surface sites upon adsorption, with consequent electrostatic repulsion and steric hindrance (Danielsson et al., 2018). Such NOM sorption is inversely $\mathrm{pH}$ dependent, with increasing electrostatic repulsion at $\mathrm{pH}>8$, since NOM molecules become highly ionized and thus negatively charged, similar to $\mathrm{TiO}_{2}$ NPs (Mwaanga et al., 2014). Bioavailability (and toxicity) of $\mathrm{TiO}_{2} \mathrm{NPs}$ may also depend on the specific fraction of NOM, which preferentially sorb onto $\mathrm{TiO}_{2}$ NPs. Mwaanga et al. (2014) reported a higher sorption of NOM compounds characterized by high molecular weight to $\mathrm{TiO}_{2}$ NPs, regardless of NOM concentration. This is in agreement with studies on other engineered NPs, showing that NP stability increases in the presence of NOM with high molecular weight (Louie et al., 2015). However, the stabilizing effect of NOM can be masked in high ionic strength media, in which $\mathrm{TiO}_{2}$ aggregation is favored by the interaction with divalent cations, which can lead to specific ion-NOM bridges (Romanello and Fidalgo de Cortalezzi, 2013; Luo et al., 2018).

The effect of ocean acidification on $\mathrm{TiO}_{2}$ agglomeration dynamics in the marine environment has been evaluated by Shi et al. (2019). With respect to nanoscale agglomerates (average of $334.8 \mathrm{~nm}$ ) formed in NSW at an ambient $\mathrm{pH}$ of 8.1, the authors observed an increase in $\mathrm{TiO}_{2} \mathrm{NP}$ size at lower $\mathrm{pH}$, reaching an average of 439.8 and $537.1 \mathrm{~nm}$ at $\mathrm{pH}$ of 7.8 and 7.4 , respectively. These results suggest that, under future ocean acidification scenarios, these anthropogenic NPs as large agglomerates could further change their behavior and are bioavailable to different species.

\section{PS NP Behavior in Seawater Media}

Several ecotoxicity studies reported the characterization of PS NP behavior in filtered NSW in simplified enclosed systems under controlled laboratory conditions, but with the attempt to mimic natural environmental conditions. These studies indicate that nanoplastic behavior and fate in temperate coastal regions mainly depend on their size and surface functionalization, with major differences observed between plain PS and PS-COOH vs. PS- $\mathrm{NH}_{2}$ NPs, as reported below.

Negatively charged PS NPs, such as PS-COOH NPs, are usually prone to agglomerate in the range of $0.9-1.8 \mu \mathrm{m}$ soon after dispersion in aqueous media characterized by high ionic strength $(>38 \% 0)$, basic $\mathrm{pH}$, and NOM. Such agglomeration phenomena are largely supported by the DLVO theory and related extensions (Cai et al., 2018; Singh et al., 2019; Wu et al., 2019). Examples are represented by microalgae culture medium (Bergami et al., 2017) and NSW (Della Torre et al., 2014; Bergami et al., 2016; Manfra et al., 2017; Tallec et al., 2018; Grassi et al., 2019), where slight differences in NP agglomerates and size distribution are potentially related to the spatial and temporal variability in seawater chemical composition (i.e., organic matter and ions). In the studies mentioned above, large agglomerates of PS-COOH NPs were related to a wide size distribution and a reduced negative surface charge, as suggested by low $\zeta$-potential values, corresponding to about $-10 \mathrm{mV}$, compared to their values in ultrapure water, up to $-66 \mathrm{mV}$ (Bergami et al., 2017). Contrary to these previous works, González-Fernández et al. (2019) observed that PS-COOH NPs in seawater kept a small hydrodynamic size, which was stable for $5 \mathrm{~h}$. The authors hypothesized that the different behavior in NSW was related to complex NP-environmental interactions, although the variability in PS NP intrinsic properties, such as particle density $\left(1.03 \mathrm{~g} / \mathrm{cm}^{3}\right.$ vs. $1.05-1.06 \mathrm{~g} / \mathrm{cm}^{3}$ in previous studies) or experimental conditions (constant rotation vs. static test in previous studies), might have dictated such different agglomeration.

Plain PS NPs with no functionalization typically exhibited a negative surface charge and a behavior in NSW similar to PSCOOH NPs, with a slight (Brandts et al., 2018) or pronounced (Tallec et al., 2018; Ciacci et al., 2019) increase in the average hydrodynamic size with respect to their optimal dispersion in ultrapure water, as well as a decrease in absolute $\zeta$-potential. Stability of plain PS NPs in NSW has been reported in the first hours after the preparation of the suspensions (Mishra et al., 2019), though time-dependent agglomeration that occurred later at 24 and $48 \mathrm{~h}$ (Brandts et al., 2018; Tallec et al., 2018; Mishra et al., 2019). From DLS data, Brandts et al. (2018) also suggested the sorption capacity of carbamazepine, one of the most common pharmaceuticals found in the environment, onto PS NPs, while NP interaction with heavy metals mostly depends on their speciation in the aquatic environments (Singh et al., 2019). Differently from plain and PS-COOH NPs, once suspended in NSW, positively charged PS NPs usually display a hydrodynamic size close to their nominal diameter (Wu et al.,

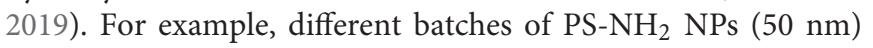
from the Bangs Laboratories Inc., kept an average hydrodynamic size ranging from 58 to $196 \mathrm{~nm}$ in different NSW media from the Mediterranean region (Della Torre et al., 2014; Bergami et al., 2016, 2017; Manfra et al., 2017; Pinsino et al., 2017; Marques-Santos et al., 2018; Grassi et al., 2019), thus showing no or slight agglomeration soon after dispersion. However, timeresolved DLS measurements revealed a strong agglomeration behavior of PS- $\mathrm{NH}_{2}$ in NSW after 48 and $72 \mathrm{~h}$, with large aggregates up to $5 \mu \mathrm{m}$, which were more prone to sedimentation (Varó et al., 2019).

In terms of interaction with NOM, HA was found to stabilize negatively charged PS-based nanoplastics (100 nm), such as plain PS and PS-COOH NPs, due to electrostatic repulsion between negative charges and steric effect (Wu et al., 2019). On the contrary, once adsorbed onto positively charged PS- $\mathrm{NH}_{2} \mathrm{NPs}$, $\mathrm{HA}$ was able to reverse the surface charge at HA concentrations above $5 \mathrm{mg} \mathrm{L}^{-1}$, inducing PS- $\mathrm{NH}_{2}$ to agglomerate at $10 \mathrm{mg} \mathrm{L}^{-1}$ HA (Wu et al., 2019). Divalent cations (e.g., $\mathrm{Ca}^{2+}$ and $\mathrm{Mg}^{2+}$ ) present in seawater can induce higher agglomeration of PS NPs, compared to monovalent ones $\left(\mathrm{Na}^{+}\right.$) (Cai et al., 2018; Singh et al., 2019). In a $\mathrm{CaCl}_{2}$ solution containing $\mathrm{HA}$, high ionic valence was found to facilitate bridging effect between nanoplastics and HA, enhancing complexation (Singh et al., 2019). PS NPs (25 nm) 
with different surface functionalization have also been shown to easily assemble with DOM in NSW due to hydrophobic interactions, with potential repercussions on carbon dynamics in marine environments even at low NP concentrations $\left(10 \mu \mathrm{g} \mathrm{L}^{-1}\right)$ (Chen et al., 2018).

In nano-ecotoxicity studies, the analysis of NP aggregation kinetics and stability in aqueous suspensions over time is crucial to correctly interpret the biological effects observed, toward a more reliable environmental risk assessment. It is important to underline that the considerations from the studies reported are referred to temperate coastal regions and may be extended to tropical regions, although more case studies focusing on NP characterization under different environmental conditions are needed.

In polar marine environments, additional factors, such as the low sea surface temperature (below $0^{\circ} \mathrm{C}$ ) and the interaction with sea ice may play an important role in determining the behavior and fate of anthropogenic NPs, although they have been poorly studied. Bergami et al. (2019) measured the size parameters of functionalized PS NPs in NSW collected from a coastal region in the maritime Antarctic. Secondary characterization in Antarctic NSW (salinity $34 \% 0$ and $\mathrm{pH} 8.0$ ) revealed the initial formation of PS nano-scale agglomerates in NSW at $0^{\circ} \mathrm{C}$, increasing over time until an average of 835 and $452 \mathrm{~nm}$, for PS-COOH and PS$\mathrm{NH}_{2}$ NPs respectively. Additionally, when PS NP suspensions were incubated at $-20^{\circ} \mathrm{C}$ for $12 \mathrm{~h}$, broad size distributions were found, with a higher effect observed for positively charged PS- $\mathrm{NH}_{2}$ (Bergami et al., 2019). On the contrary, the same batch of PS-COOH quickly reached micrometer agglomerates in filtered NSW from the Tyrrhenian Sea (Mediterranean region, salinity $38 \%$ and $\mathrm{pH} 8.3$ ) at temperatures ranging from $18^{\circ} \mathrm{C}$ (Della Torre et al., 2014) to $25^{\circ} \mathrm{C}$ (Bergami et al., 2016). An explanation for this difference may be related to the increase in kinetic energy at higher temperatures, resulting in higher collision frequency and instability of the nanoplastics (Singh et al., 2019), which are more prone to agglomerate. The first data under Antarctic-like conditions suggest that low temperatures and salinity may significantly affect nanoplastic behavior, calling for further investigation.

\section{INTERACTION WITH LIVING SYSTEMS: THE CORONA CONCEPT}

Recent experimental evidence points out that many variables concur to determine the outcome of bio-nano interactions in seawater, both with a physical-chemical and biological relevance, and therefore delineating the ecotoxicity of NPs in such complex water matrices (Figure 1). With decreasing dimension, the surface area-to-volume ratio exponentially increases, leading to the presence of a higher number of atoms at the surface compared to the core of the NP. Interfacial properties are key determinants of NP reactivity, given the high portion of material exposed to the exterior and, hence, able to engage in chemical and physical reactions with other nanoscale objects or molecules. With such maximized exposure to the external environment, the particle interface is where all the processes defining the
NP interaction with surrounding (biological) entities take place. The high surface free energy that characterizes NPs drives their interactions in order to lower such energy levels. Consequently, NPs are naturally prone to interact with biological and abiotic entities, which they encounter in the surrounding medium, as a means to achieve a more energetically favorable configuration (Petosa et al., 2010). The dynamics of protein adsorption onto surfaces has first been described by the Vroman effect (Vroman, 1962), which can be used to explain the interfacial interactions occurring when NPs are in biological milieus. On such basis, the interactions of NPs with biological molecules took shape in the biomolecule "corona" (also termed bio-corona) paradigm, as initially described by the coating of NPs by a layer of adsorbed proteins, derived from a biological environment (Cedervall et al., 2007b). Although foundational corona studies tackled the protein fraction, biomolecular coronas were shown to contain lipids (Lara et al., 2017) and saccharides (Wan et al., 2015). Moreover, as biomolecule adsorption onto NPs is a dynamic process, protein corona is regarded as a continuously evolving entity. Different protein species display distinct binding affinities for one specific NP surface, and an evolution of corona composition over time is usually observed. Generally, the most abundant proteins in the incubation media rapidly bind on the NP surface, often being displaced by species characterized by higher affinities (Cedervall et al., 2007a), until a "mature" protein corona composition is achieved (Casals et al., 2010; Monopoli et al., 2013). Commonly, the biomolecular corona is viewed as a slowly exchanging and tightly bound layer of biomolecules adsorbed on the NP surface, also termed the "hard" corona, whose composition is in equilibrium with the surrounding environment and sufficiently long lived to provide the NP with a molecular fingerprint, namely, the biological identity of NPs. Additionally, an outermost cloud of loosely bound molecules with lower binding affinities, called the "soft corona," is in rapid exchange with the environment (Milani et al., 2012; Winzen et al., 2015). Quantitative analysis reveals that only few protein species usually prevails in the overall corona composition (Kokkinopoulou et al., 2017). On top of peculiar molecule characteristics (e.g., isoelectric point, molecular weight, tertiary structure, charge distribution), NP physical-chemical features are key determinants of the biomolecular corona composition. The NP surface charge has been proven to exert a strong influence on the composition of biomolecular coronas due to electrostatic effects (Lundqvist et al., 2008; Walkey et al., 2012; Tenzer et al., 2013; Ritz et al., 2015). Moreover, NP surface charge interacts with the peculiar local charge distribution of proteins, determining their binding affinities and orientation when adsorbed on the NP surface (Shang and Nienhaus, 2017). NP size, determining the specific surface curvature, influences the amount and type of proteins forming the biomolecular corona, by spatial constraints and crowding effects (Dobrovolskaia et al., 2009; Tenzer et al., 2011; Goy-López et al., 2012; Piella et al., 2017). Accordingly, the peculiar NP shape and topology greatly influence the biomolecular corona qualitatively and quantitatively (Albanese et al., 2012; GarcíaÁlvarez et al., 2018). Along with intrinsic and extrinsic NP characteristics, factors defining the boundary conditions to NPbiomolecule interactions are important in determining their 

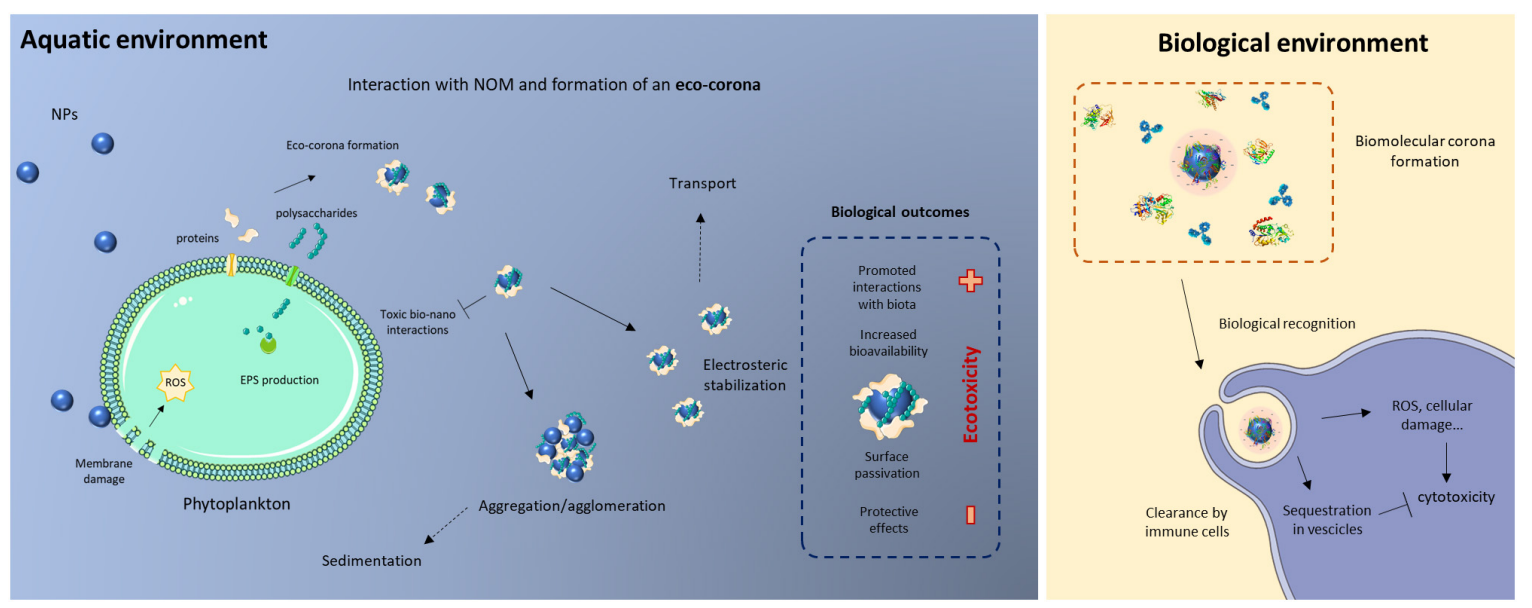

FIGURE 1 | Schematic illustration of the bio-nano interactions taking place in the marine environment. Left: possible interactions between nanoscale particles (NPs) dispersed in seawater and biomolecules making up the marine natural organic matter (NOM) pool, such as microalgal/cyanobacterial extracellular polymeric substances (EPS). Right: the cellular processes following biomolecular corona formation in biological fluids of marine invertebrate organisms.

outcomes. For instance, protein abundance and the relative ratio of NP surface area to the biological fluid volume can dictate the quantity and quality of adsorbed proteins (Caracciolo et al., 2011; Monopoli et al., 2011). Furthermore, exposure time (Casals et al., 2010), temperature (Mahmoudi et al., 2013), and chemical composition (Eigenheer et al., 2014) of the incubation medium play an important role in the corona formation. Moreover, such elements can determine the NP suspension stability and induce aggregation of NPs in the biological milieu, in turn influencing protein adsorption and organization within the aggregates, and finally the biodistribution of NP-protein complexes (Mohr et al., 2014; Kokkinopoulou et al., 2017; Lundqvist et al., 2017).

\section{The Role of the Biomolecular Corona in Nanoecotoxicology}

The introduction of the biomolecular corona concept, upon which has nowadays been reached a wide consensus among the scientific community, has led to a change in paradigm regarding how NPs are viewed in relation to biological systems. The rapid adsorption of proteins and other biomolecules can confer to NPs a new biological identity dictated by biomolecular species at the NP surface, remarkably different from the intrinsic, welldefined chemical one. By providing a first point of contact with cells, the biomolecular corona functions as a bridge in bio-nano interface. The fate of NPs in biological systems, be they cells, organs, or whole organism, is mediated by the adsorbed proteins species, which direct the NP toward specific pathways, deeply affecting subsequent events at the molecular level (Verma and Stellacci, 2010). Although the primary importance of biomolecular coronas has long been acknowledged in the biotechnological and biomedical fields, its potential in understanding nano-(eco)toxicology has only been recently recognized. Indeed, "traditional" ecotoxicity assessment, when applied to NPs, often fails to provide a comprehensive representation of toxicity, as objects at the nanoscale are intrinsically different entities compared to classical toxicants. In this regard, the protein corona paradigm can be incorporated into the field of ecotoxicology (Lynch et al., 2014). As reported in recent works, this concept has been fruitfully applied in the ecotoxicological studies concerning different NP types. For instance, the effect of protein adsorption on Ag NPs was found to be an important molecular determinant of toxicity toward fish gill cell lines in their physiological environment (Yue et al., 2015, 2016a). Moreover, the analysis of the protein corona formed in the intracellular environment of rainbow trout (Oncorhynchus mykiss) gill cells showed a fingerprint of the interactions of Ag NPs with different subcellular compartments and provided useful insight on mechanism of toxicity (Yue et al., 2016b). The incubation of PVP-coated Ag NPs in the blood plasma of male and female smallmouth bass Micropterus dolomieu resulted in the formation of a gender-specific corona and allowed for postulation of hypothetical distribution within different body compartments (Gao et al., 2017). Also, invertebrate species have been considered in ecotoxicity studies, encompassing the formation and characterization of biomolecular coronas. Hayashi and coworkers exposed $\mathrm{SiO}_{2}$ and $\mathrm{Ag}$ NPs to the native protein repertoire of the earthworm Eisenia fetida demonstrating that the resulting protein corona assists cellular interactions (Hayashi et al., 2013). More recently, the importance of the study of biomolecular coronas in the biological fluids of invertebrate species as a means of understanding their environmental impact was stressed (Canesi et al., 2017).

Marine invertebrates are primary targets of NPs entering seawater coastal ecosystems and can provide insights in the mode of action of NP toxicity. Therefore, marine invertebrate species have been recommended and successfully employed in ecotoxicity studies with different NP types (Matranga and Corsi, 2012; Canesi and Corsi, 2016; Canesi et al., 2016a). As such, they provide an interesting platform to translate the study of biomolecular coronas into a concrete understanding of NP impact on the marine environment, advancing an ecological 
risk assessment. For instance, marine mussels have been largely exploited in marine nano-ecotoxicology, and more recently, their biological fluids have been used for biomolecular corona studies (Canesi et al., 2015, 2017; Auguste et al., 2019). In the marine mussel Mytilus galloprovincialis, it was demonstrated that the presence of a biomolecular corona acquired in the organism hemolymph, composed by the $\mathrm{Cu}, \mathrm{Zn}-\mathrm{SOD}$ protein, clearly augmented toxicological responses in immune cells, compared to the corona-free counterparts (Sendra et al., 2018). In another study, cytotoxic effects toward M. galloprovincialis hemocytes, triggered by the exposure to aminated PS NPs (PS- $\left.\mathrm{NH}_{2}\right)$, were ascribed to the extrapallial protein (EP) precursor (MgC1q6) that dominated the protein corona, which has known opsonization functions and is envisaged to facilitate NP-cell interactions (Canesi et al., 2016b). Marine mussels produce mucus as first line of defense from environmental stressors, with the ability to trap and sort exogenous particulate materials, as a means to prevent possible noxious interactions (Beninger and St-Jean, 1997; Espinosa et al., 2010). Therefore, mucus represents an important defense mechanism against NPs in seawater. It was demonstrated that a panel of $\mathrm{TiO}_{2}$ NPs with different shapes, sizes, $\zeta$ potentials, and crystal structures (anatase vs. rutile), exposed to the same mucus protein repertoire of Mytilus edulis, formed biomolecular coronas with different protein patterns, depending on such characteristics (Bourgeault et al., 2017). In particular, adsorption of proteins was quantitatively different among $\mathrm{TiO}_{2}$ NP types, and the protein signatures revealed the absence in the corona of the principal mucus component (the EP protein), unable to adsorb due to stiffness of its structure stemming from the high content of aromatic residues. On the contrary, the presence of some stress-related protein species, whose affinity for different $\mathrm{TiO}_{2}$ NPs appeared to be crystal structure and shape dependent, suggested the acquisition of a new biological identity. Moreover, larger particles readily adsorbed higher protein amount per surface unit, suggesting that quantitative aspects of the protein corona should be accounted for in ecotoxicity studies.

Sea urchins have been largely employed in marine ecotoxicological studies. In this regard, the sea urchin immune system has been exploited in assessing the effect of various toxicants in marine ecosystems, being regarded as an exploratory tool for identifying the mechanism of immune response to environmental stresses (Matranga et al., 2005; Pinsino and Matranga, 2015). As to nano-ecotoxicology, sea urchin immune cells were used for probing the toxicity of different NP types (Falugi et al., 2012; Pinsino et al., 2015). The immunobiology of sea urchin has been defined as among the most complex within marine invertebrate species, qualifying the sea urchin as proxies for the study of NP-triggered immune reactions preluding to ecotoxic effects (Alijagic and Pinsino, 2017). NP-biomolecule complexes in environmentally relevant model species can be exploited to achieve a clearer image of NP ecotoxicology and advance our understanding of their environmental impact, and the use of sea urchins entails the potential to translate such findings to more complex organisms. In this light, Alijagic et al. (2020) depicted a comprehensive picture of the Mediterranean Sea urchin Paracentrotus lividus immune system adaptation to
$\mathrm{TiO}_{2} \mathrm{NP}$ exposure by downregulating genes involved in the inflammatory immune response and increasing immune cell antioxidant capacity (Alijagic et al., 2020). Focusing on bio-nano interactions, Marques-Santos et al. (2018) described the effect of a calcium-binding, transferrin-like protein, adsorbed onto PS- $\mathrm{NH}_{2}$ NPs incubated in coelomic fluid, on its immune system. Specifically, the toposome, with known cell adhesion functions, seemed to facilitate cell interactions and PS- $\mathrm{NH}_{2} \mathrm{NP}$ clearance from the coelomic fluid by phagocytic coelomocytes, which, in turn, sustained related cytotoxic effects. The biomolecular corona of positively and negatively charged PS NPs (PS- $\mathrm{NH}_{2}$, $50 \mathrm{~nm}$ and PS-COOH, $62 \mathrm{~nm}$ ) in P. lividus coelomic fluid was thoroughly assessed by a classical proteomic approach revealing a strikingly similar corona composition between the two particles. The abundance of cytoskeletal proteins and species involved in cell adhesion processes strengthened the hypothesis of an active role of the protein corona in the association with sea urchin immune cells and phagosome formation, as evidenced by the Kyoto Encyclopedia of Genes and Genomes (KEGG) pathway analysis, suggesting a similar internalization pathway of NP with different surface charges (Grassi et al., 2019). In a following similar study, the same protein species were recovered from the surface of $\mathrm{P} 25 \mathrm{TiO}_{2} \mathrm{NPs}$ incubated in P. lividus coelomic fluid (Alijagic et al., 2019). In particular, toposome, nectin and different actin isoforms were common constituents of both PS NPs, as previously identified, and $\mathrm{TiO}_{2}$ NPs corona, suggesting a non-discriminative adsorption of $P$. lividus extracellular proteins on inherently different NPs, and postulating the same cell adhesion and internalization mechanisms toward by immune cells.

\section{NP Bio-Interactions in Marine Waters: Introduction to the Eco-Corona Concept}

Nanoscale particles entering aquatic ecosystems will likely be received by different environmental compartments prior to contacting biota. For instance, NPs entering natural water compartments will undergo substantial modifications as dictated by the characteristics of the receiving media. Along with the welldocumented effects on colloidal stability with different outcomes on behavior and fate, increased emphasis has recently been placed on the processes occurring at the interface between NPs and the environment. Biomolecule-rich abiotic environmental compartments, such as marine water bodies, represent dynamic environments where NPs interact with biological entities. The organic component of natural waters is composed of a highly heterogeneous group of biomolecules which can be categorized as allochthonous and autochthonous compounds (Docter et al., 2015). The degradation byproducts of organic material of plant origin, mainly composed of high molecular weight $\mathrm{HA}$ and FA, belong to the former category. In contrast, autochthonous $\mathrm{NOM}$ is the ensemble of biomolecules produced in situ by living organisms, such as bacterial and microalgal communities, which are huge contributors to the organic macromolecule pool of natural waters (Gutierrez et al., 2018). Their exudates, collectively termed EPS (extracellular polymeric substances), mainly consist of a variety of high molecular weight polysaccharides, and 
to a lesser extent of glycoproteins, lipids, and nucleic acids. The composition of the organic fractions encountered in seawater spans across a wide spectrum of molecular weights, taking shape in a continuum of sizes from amino acids to peptides and polysaccharides, encompassing truly dissolved and colloidal/macromolecular species (Verdugo et al., 2004; Wilkinson and Lead, 2007).

Additionally, due to the different contributions to the NOM pool, the chemical makeup of organic biomolecules is exceptionally heterogeneous, with tens of thousands of unique chemical species, contributing to the overall complexity of the marine water matrix (Mopper et al., 2007; Ortega-Morales et al., 2007). The interactions of NPs in natural waters with the totality of NOM can lead to the formation of diverse biomolecular coatings, collectively termed the "eco-corona," analogous to the bio-corona previously described in purely biological fluids (Lynch et al., 2014). For instance, the interaction of organic molecules with NPs dispersed in seawater can result in their inclusion into biomolecular matrices, occurring either as composite organic networks embedding single particles or aggregates into microgel-like structures (Figures $\mathbf{2 b , e )}$ or as tightly adsorbed layers at the surface (Figures 2c,f), as shown for $\mathrm{TiO}_{2}$ and PS-COOH NPs.
Dispersion in natural waters usually confers some degree of polydispersity, complicating the interaction with natural biomolecules. Aggregation phenomena often occur, and NP aggregates/agglomerates will be present, together with monomers, giving rise to multifaceted interactions with the NOM matrix. In general, NOM molecules can either promote the aggregation of stable NP suspensions in natural waters or limiting the aggregation phenomena by providing steric stabilization (Nason et al., 2012; Surette and Nason, 2016, 2019; Danielsson et al., 2018). Therefore, aggregation and biomolecule adsorption can represent competing phenomena in seawater, where high salinity can induce aggregation, while eco-corona formation may disrupt such phenomena. Under such conditions, the result of NOM-NP interaction cannot be viewed simply as the formation of a uniform molecular layer at the particle surface, but rather a more complex organization of NPs in the NOM matrix can be expected.

The importance of an acquired eco-corona in shaping the nanotoxicity of different NP types has recently been acknowledged (He et al., 2018, 2015). In fact, the acquisition of an eco-corona from the surrounding environment is expected to modify key NP parameters, possibly rebounding on nanotoxicity (Ren et al., 2016), and the inclusion of such variables in the

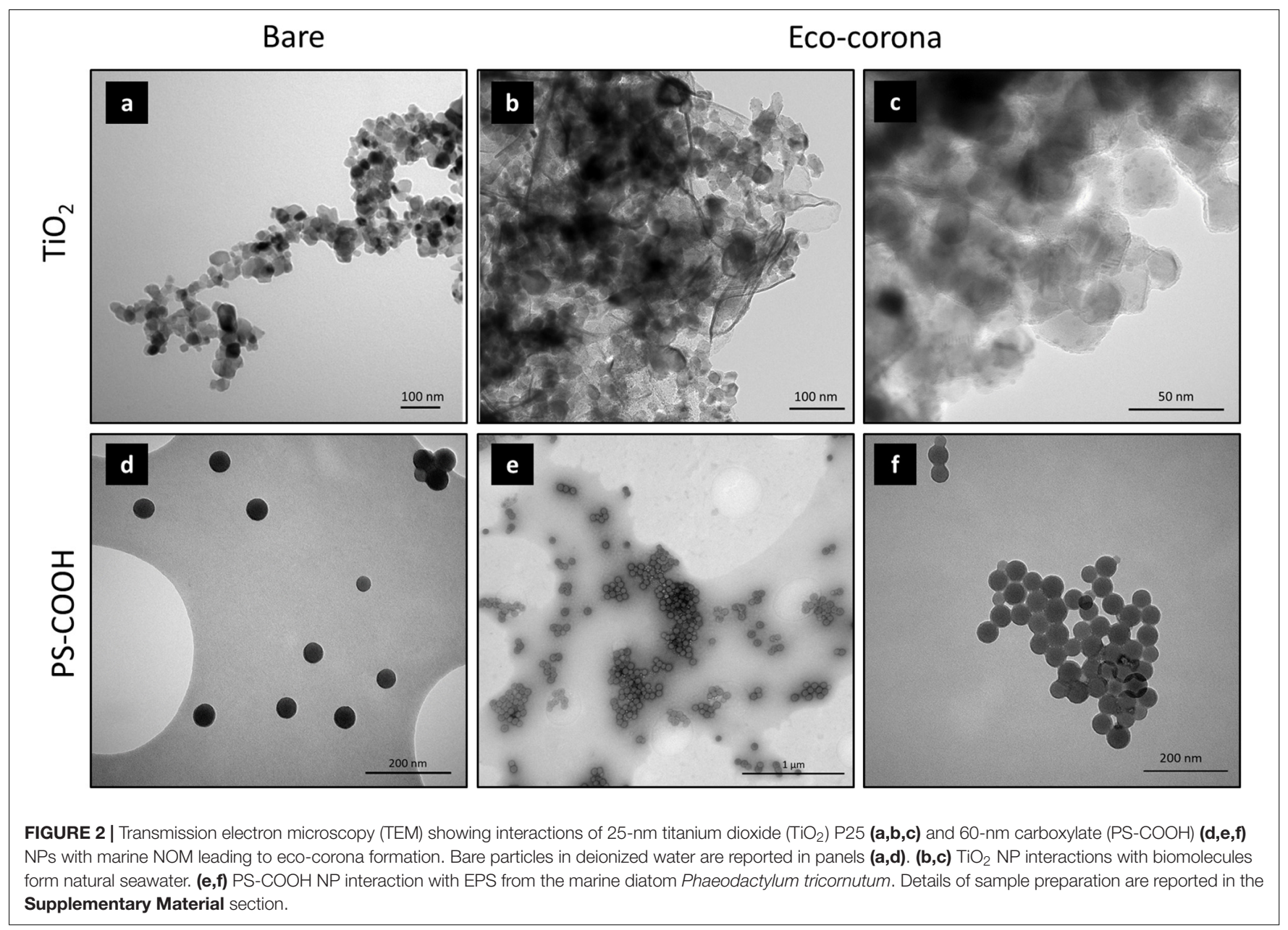


ecotoxicity testing of NP is strongly encouraged to gather ecologically meaningful results (Holden et al., 2016). Recently, proofs of concept were provided by supplementing ecotoxicity test media with exogenous NOM surrogates (e.g., commercially available humic/fulvic fractions and proteins), thus provoking eco-corona formation. In particular, NOM and BSA mitigated the toxicity induced by $\mathrm{ZnO}$ and $\mathrm{MnO}_{2}$ NPs toward oyster (Crassostrea gigas) embryos by interfering with dissolution and bandgap mechanisms (Noventa et al., 2018). Morelli et al. (2018) isolated the EPS produced by the marine microalgae Dunaliella tertiolecta, probing the selective adsorption of proteins on the surface of $\mathrm{P} 25 \mathrm{TiO}_{2} \mathrm{NPs}$, shaping an eco-corona (2018). The EPS from the marine bacterium Pseudomonas aeruginosa was able to clearly mitigate the toxic effect of the same NP type mainly by delaying the oxidative damage caused by reactive oxygen species (ROS) produced in seawater (Hessler et al., 2012).

\section{EFFECTS ON MARINE ORGANISMS}

According to the vast number of ecotoxicity studies on $\mathrm{TiO}_{2}$ $\mathrm{NP}$, oxidative stress is largely recognized as the main mechanism of toxicity in marine species, although other biological effects have been recorded (Figure 3A; Minetto et al., 2014, 2016; Xia et al., 2015). Based on most recent studies in which $\mathrm{TiO}_{2} \mathrm{NP}$ characterization have been included in order to address exposure scenario in the observed toxicity, the largest efforts concentrated on both marine plankton (42.1\%) and benthos (44.7\%) and only a minority on marine fish (13.2\%) (Figure 3A; see Supplementary Material section for literature cited).

The first record on $\mathrm{TiO}_{2}$ ecotoxicity has been provided on marine phytoplanktonic species as cyanobacteria and green algae in which the role of light and consequently photoactivation has been linked to membrane damage, oxidative stress, genotoxicity, and inhibition of growth. According to Miller et al. (2010), no effect is observed in marine diatoms in the range between 10$1,000 \mu \mathrm{g} \mathrm{L}^{-1}$ unless $\mathrm{UV}$ is inducting $\mathrm{TiO}_{2} \mathrm{NP}$ photoactivation (Miller et al., 2012). UV-A light is able to energize $\mathrm{TiO}_{2} \mathrm{NP}$ and to photoinduce the generation of reactive oxygen radicals in exposed cells (Uchino et al., 2002; Sayes et al., 2006). UVA exposure ( $6 \mathrm{~h}$ per day), rather than visible light, is reported to strongly affect sensitivity of the marine algae Phaeodactylum tricornutum to $\mathrm{TiO}_{2} \mathrm{NP}$ compared to bulk form due to increased production of reactive oxygen species (ROS) (Sendra et al., 2017a). Chloroplasts of the algae Karenia brevis have been identified as the site of ROS induced by $\mathrm{TiO}_{2}$ exposure with consequent increase in lipid peroxidation and cell damage leading to inhibition of algal growth (Li et al., 2015). On the other hand, according to Bhuvaneshwari et al. (2017), the formation in seawater of large $\mathrm{TiO}_{2}$ agglomerates significantly reduced the $\mathrm{TiO}_{2}$ phototoxicity under UV-A irradiation in brine shrimp Artemia salina. An increase in ROS generation and antioxidant enzymes is supposed to drive $\mathrm{TiO}_{2}$ phototoxicity in green algae Dunaliella salina and brine shrimp larvae A. salina upon waterborne exposure (Bhuvaneshwari et al., 2018). Minetto et al. (2017) further support the role of light, which significantly affect $\mathrm{TiO}_{2}$ toxicity on marine algae. According to Pellegrino et al. (2017), $\mathrm{TiO}_{2}$ aggregation and agglomeration significantly reduce light adsorption by causing diffusion of the incoming radiation. Sun et al. (2014) previously demonstrated that UV irradiation of P25 $\mathrm{TiO}_{2}$ water suspensions enhances particle aggregation by increasing surface concentration of hydroxyl groups, which lower the isolectric point and reduce positive charges of $\mathrm{TiO}_{2}$. More recently, Budarz et al. (2017) showed that the photoreactivity and aggregation of $\mathrm{TiO}_{2} \mathrm{NPs}$ are strongly influenced by anionic species present in the water media with carbonate and chloride having a strongest role in suppressing hydroxyl radical generation by substituting hydroxyl ions. The fast agglomeration/aggregation of $\mathrm{TiO}_{2} \mathrm{NPs}$ in high ionic media such as sea water is also having a significant role in $\mathrm{TiO}_{2}$ properties and therefore toxicity for marine species (Brunelli et al., 2013). A physical interaction of $\mathrm{TiO}_{2}$ agglomerates by entrapping green algae $P$. tricornutum is considered the main driver of toxicity according to Deng et al. (2017); Wang et al. (2017). An increase in oxidative stress and the inhibition of the effective quantum yields are foreseen as a defense mechanism used by algae toward physical damage caused by $\mathrm{TiO}_{2}$ agglomerates (Hu et al., 2018). Surface adhesion of $\mathrm{TiO}_{2}$ agglomerates to the microalgae Nitzschia closterium is thought to be responsible for $\mathrm{TiO}_{2}$ trophic transfer to the scallop Chlamys farreri (Wang et al., 2017). Fast sinking of $\mathrm{TiO}_{2}$ agglomerates can explain the absence of toxicity to the larvae of rotifer Brachionus plicatilis and of the brine shrimp A. salina according to Nogueira et al. (2015). Moreover, no effect on embryo development was observed at concentrations above $1 \mathrm{mg} \mathrm{L}^{-1}$ in marine bivalve M. galloprovincialis (Libralato et al., 2013; Balbi et al., 2014). A time-dependent process of $\mathrm{TiO}_{2}$ agglomeration is reported by Morelli et al. (2018) as well as the mitigation role played by algal EPS in the fast $\mathrm{TiO}_{2} \mathrm{NP}$ agglomeration. Other sources of NOM, such as for instance the mucus secreted by bivalve's gills, can affect the formation of $\mathrm{TiO}_{2}$ agglomerates, which are then translocated to the digestive gland by hemolymph and then excreted with pseudofeces (Wang et al., 2014; Canesi and Corsi, 2016). In this regard, evidence of $\mathrm{TiO}_{2} \mathrm{NP}$ localization in the cytoplasm and vacuoles of bivalve's immune cells raises further concern due to their widely reported $\mathrm{TiO}_{2} \mathrm{NP}$ immunomodulatory effects both in vitro and in vivo (i.e., endo-lysosomal system and phagocytic activity) (reviewed in Marisa et al., 2015; Canesi and Corsi, 2016; Shi et al., 2017; Guan et al., 2018; Canesi et al., 2019).

High and fast body clearance ( $<90 \%$ within $12 \mathrm{~h}$ ) of two $\mathrm{TiO}_{2} \mathrm{NP}$ formulations (Titan and P25) is reported in blue mussel (M. edulis) and oyster (Crassostrea virginica) regardless of the form of delivery (marine snow vs. suspensions) upon waterborne exposure (6 h) (Doyle et al., 2015). In addition, less than $10 \%$ of the nominal concentration of $\mathrm{TiO}_{2}$ is supposed to be available to marine species due to particle sedimentation and agglomeration/adsorption processes occurring in the presence of organic matter produced by marine organisms (EPS, mucus, pseudofeces).

Despite a certain number of studies that recognized $\mathrm{TiO}_{2}$ ecotoxicity for marine species, a few of them investigated those $\mathrm{TiO}_{2}$ formulations, which are released from commercial products, which also undergo such transformations (i.e., weathering and aging) able to affect their behavior and 
A

Physical effects

Growth

Photosynthesis

Oxidative stress

Genotoxicity

Trophic transfer
$\mathrm{TiO}_{2}$

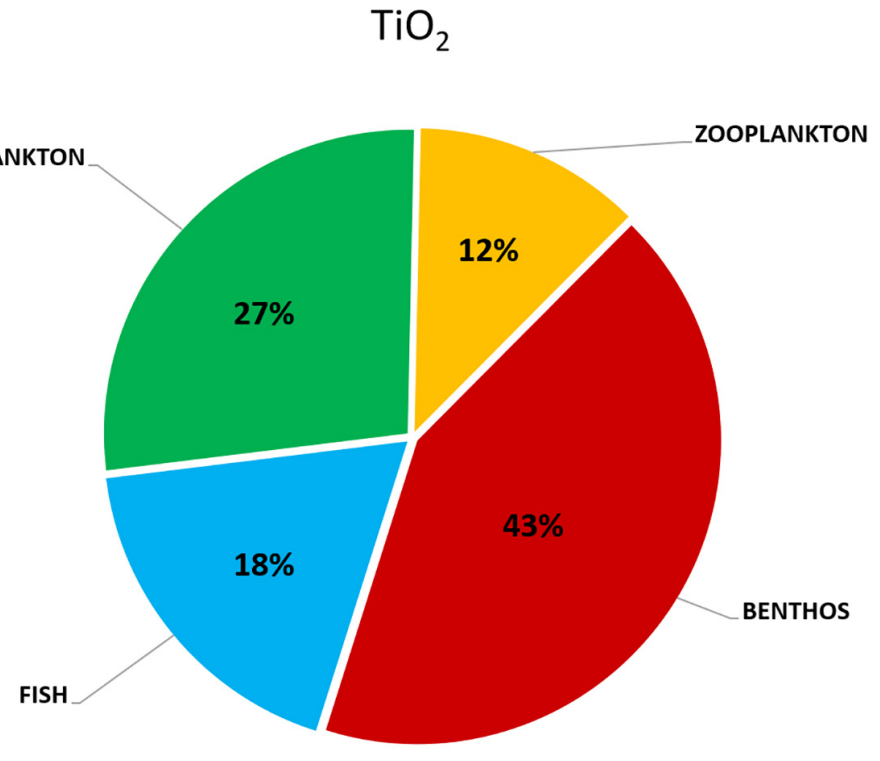

Physical effects

Development

Embryotoxicity

Reproduction

Motility

Oxidative stress
Physical effects Translocation

Oxidative stress Immunomodulation

Neurotoxicity Trojan horse effect

B

Physical effects

Growth

Photosynthesis

Trophic transfer

Oxidative stress

Trojan horse effect

Energy reserves

Physical effects

Translocation

Oxidative stress

Genotoxicity

Immunomodulation

Trophic transfer

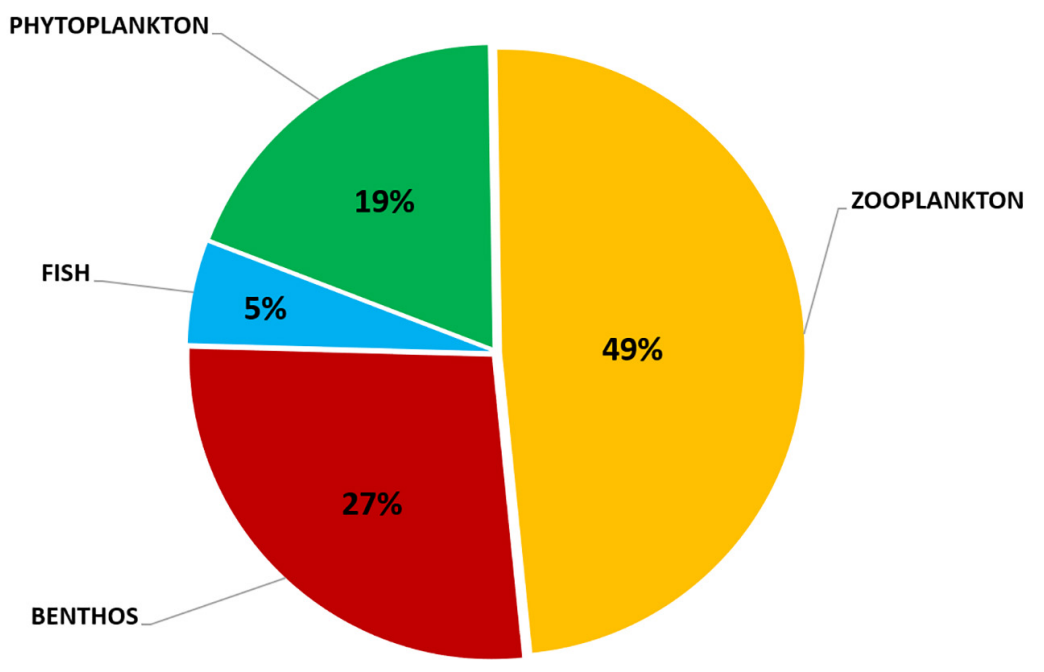

Physical effects

Development

Embryotoxicity

Reproduction

Motility

Oxidative stress

Genotoxicity

Efflux pumps

FIGURE 3 | Schematic representation of the distribution of taxa investigated in ecotoxicity studies [(A) $\mathrm{TiO}_{2}$ and (B) polystyrene (PS) NPs] and related documented effects. Please refer to Supplementary Material section for details on literature used. Total number of studies was 37 for $\mathrm{PS}$ and 38 for $\mathrm{TiO}_{2}$.

interaction with marine biota (Labille et al., 2010; Nowack and Mitrano, 2018). Gondikas et al. (2014) first showed the release of $\mathrm{TiO}_{2}$ from sunscreen formulations in lake surface waters raising concern regarding effects on aquatic species. $\mathrm{TiO}_{2}$-based sunscreen products have been shown to be more toxic to marine planktonic diatoms under direct sunlight exposure compared to classical formulation (Sendra et al., 2017b). Oxidative damage and hydrogen peroxide production have been recorded in marine diatoms upon $\mathrm{TiO}_{2}$ exposure in association with organic compounds present in sunscreen formulation (Tovar-Sánchez et al., 2013). No effects of two $\mathrm{TiO}_{2}$-based sunscreen formulations (Eusolex $^{\circledR}$ T2000 and Optisol ${ }^{\mathrm{TM}}$ ) have been reported on tropical stony Acropora coral and symbionthic algae (i.e., Symbiodinium sp.) by Corinaldesi et al. (2018), while $\mathrm{TiO}_{2}$ 
exposure was considered responsible for zooxanthellae expulsion in the Caribbean coral Montastraea faveolata (Jovanović and Guzmán, 2014). Therefore, more studies are urgently needed to disentangle the role of single nanoscale particle from the entire commercial formulation by addressing first the behavior of the particle, itself, in the natural media for defining real exposure scenarios. With this aim, several studies have been conducted for instance by evaluating the possible interactive effects of $\mathrm{TiO}_{2}$ NPs with other existing marine pollutants. Antagonistic and interactive effects have been reported both in vitro and in vivo in marine bivalve $M$. galloprovincialis (immune system, digestive gland and gills) exposed to $\mathrm{TiO}_{2}$ (Degussa P25) with cadmium and 2,3,7,8-tetrachlorodibenzop-dioxin (TCDD), respectively (Canesi et al., 2014; Della Torre et al., 2015b; Rocco et al., 2015; Banni et al., 2016). Co-exposure seemed to mitigate, rather than exacerbate, the adverse effect of single exposure with predominant antagonistic effects depending on experimental condition, cell/tissue, or type of measured response. Transcriptomic analysis in coexposure conditions revealed transcriptional changes common to individual treatments $\left(\mathrm{TiO}_{2}\right.$ and TCDD) and identified newly generated processes and response to chemical stimulus without increasing overall stressful conditions (Banni et al., 2016). The negligible adsorption of $\mathrm{Cd}^{2+}$ to $\mathrm{TiO}_{2}$ agglomerates reported upon incubation in artificial seawater probably explain the observed preferential accumulation of $\mathrm{Cd}^{2+}$ in the bivalve digestive gland and gills in the presence of $n-\mathrm{TiO}_{2}$ (Della Torre et al., 2015b). In contrast, higher TCDD accumulation was observed in whole mussel tissues in the presence of $\mathrm{n}-\mathrm{TiO}_{2}$ but not in the digestive gland. A lower benzo(a)pyrene accumulation upon co-exposure to $\mathrm{TiO}_{2}$ is reported by Farkas et al. (2015) in blue mussel $M$. edulis. Probably, B(a)P was less bioavailable to mussels due to adsorption to $\mathrm{TiO}_{2}$ agglomerates. The presence of $\mathrm{TiO}_{2}$ significantly increased the embryotoxicity of tributyltin (TBT) to the abalone (Haliotis diversicolor) (Zhu et al., 2011), and in the ark shell Scapharca subcrenata, enhanced uptake of phenanthrene is observed in the presence of $\mathrm{TiO}_{2}$ (Tian et al., 2014). On the contrary, $\mathrm{TiO}_{2}$ did not alter the bioaccumulation of several PBDE congeners in the same species (Tian et al., 2015). The few studies performed on marine fish species, underline that more studies should focus on this trophic level in order to better formulate risk assessment on marine biota. Sublethal adverse effects on the early life stages of the brackish Oryzias latipes as premature hatching, pericardial edema, and abnormal development have been reported (Paterson et al., 2011). Moreover, genotoxic and potentially cytotoxic effects were reported in Trachinotus carolinus exposed to 1.5-3 g of $\mathrm{TiO}_{2} \mathrm{NP}$ for 24, 48, and $72 \mathrm{~h}$ (Vignardi et al., 2015). In European sea bass Dicentrarchus labrax, higher levels of total Ti were found in liver upon waterborne co-exposure with TCDD $\left(46 \mathrm{pg} \mathrm{L}^{-1}\right)$ and $\mathrm{TiO}_{2}$ (1 $\mathrm{mg} \mathrm{L}^{-1}$ ) for 7 days (Della Torre et al., 2015b). At gene level, any influence of $\mathrm{TiO}_{2} \mathrm{NP}$ on TCDD ability to induce cypla and related EROD activity was found, which was further confirmed by similar levels of TCDD detected in the liver of fish upon single and co-exposure (Della Torre et al., 2015b; Vannuccini et al., 2015). On the opposite, exposure to the mixture caused a further significant downregulation of ATP-binding cassette transporter genes $a b c b 1$ and $a b c c 2$ compared to single exposure $\left(\mathrm{n}-\mathrm{TiO}_{2}\right.$ and TCDD alone) suggesting an interactive effect on $\mathrm{ABC}$, which could be a potential target of $\mathrm{TiO}_{2} \mathrm{NP}$ in liver of fish. Upon co-exposure with $\mathrm{CdCl}_{2}$ in the same experimental conditions (0.1 $\mathrm{mg} \mathrm{L}^{-1}$ and $\mathrm{TiO}_{2} 1 \mathrm{mg} \mathrm{L}{ }^{-1}$ respectively), $\mathrm{TiO}_{2}$-induced chromosomal damage and genome template instability in sea bass erythrocytes seemed reduced by the presence of $\mathrm{Cd}$, thus, supporting the hypothesis of an interactive role in co-exposure scenarios (Nigro et al., 2015).

Several laboratory studies have shown that nanoplastics (below $1 \mu \mathrm{m}$ following the classification from Hartmann et al., 2019) may cause both chemical and physical impacts to marine wildlife. In the last decade (2009-2019), PS NPs have been adopted in $85 \%$ of the ecotoxicity studies $(n=41$, listed in Supplementary Material), alongside with other polymers, mainly polymethyl methacrylate (PMMA) NPs (Bhargava et al., 2018; Brandts et al., 2018) and polyethylene (PE) nano-sized fragments (Baudrimont et al., 2019). Functionalized PS NPs, such as PS-COOH and/or PS- $\mathrm{NH}_{2}$, have been used in $44 \%$ of them to correlate the biological effects observed in the functionalization. The most common nanoplastics in the marine environment are expected to be negatively charged due to surface oxidation and acquisition of functionalities, such us the carbonyl groups, during the weathering (Fotopoulou and Karapanagioti, 2012; Gigault et al., 2016; Andrady, 2017). However, it is important to consider also positively charged nanoplastics as a counterpart since the functionalization and surface charge derived from plastic degradation products are yet to be fully determined. For example, amino modification may result from the hydrolyzation of polyamides (Merdas et al., 2003), although they are not expected to be found in high quantities in seas and oceans (Lehner et al., 2019).

The analysis of the species sensitivity to polymeric NPs, reported by Venâncio et al. (2019), showed that nanoplastics with a nominal size below $50 \mathrm{~nm}$ mainly affect marine model organisms depending on surface charge (positive vs. negative) and polymeric composition (PS vs. PMMA), suggesting that PS NPs may be more harmful than other polymers for the marine biota.

The main biological effects reported for marine model organisms exposed to PS NP suspensions are summarized in Figure 3B. Overall, a large effort has been made to study the effects on marine plankton (67.5\%), while $27 \%$ of the studies has been carried out on benthic organisms and only $5.4 \%$ on marine fish, different from microplastic studies in which these two latter categories are far more represented (Chae and An, 2017).

Studies on PS NPs and phytoplankton have usually been performed following available standardized toxicity test protocols to determine the growth inhibition at 72 or $96 \mathrm{~h}$ of an algal culture in an exponential phase exposed to a contaminant (e.g., ISO, 2006; OECD 201, 2011). Interestingly, most of the studies reported no or limited effect on microalgal growth after exposure to increasing concentrations of plain PS and PS-COOH NPs (Bergami et al., 2017; Yi et al., 2019) up to $250 \mu \mathrm{g} \mathrm{ml}^{-1}$ (Sjollema et al., 2016), while many sub-lethal physiological alterations have been observed, such as a strong adsorption of nanoplastic agglomerates on microalgal surface 
(Bergami et al., 2017; Sendra et al., 2019b; Yi et al., 2019), a decrease in photosynthesis efficiency and lipid content, as well as the production of reactive oxygen species (ROS) (GonzálezFernández et al., 2019; Sendra et al., 2019b; Seoane et al., 2019). Moreover, a significant increase in the DNA damage as well as depolarization of mitochondrial and cell membrane were found in the benthic diatom Phaeodactylum tricornutum exposed to increasing concentrations (in the range $0.1-50 \mu \mathrm{g} \mathrm{ml}^{-1}$ ) of plain PS NPs, although toxicity was not affected by their nominal sizes of 50 and $100 \mathrm{~nm}$ (Sendra et al., 2019b). Recent findings also underline how PS-COOH (50 nm) adhesion onto a diatom's surface causes a reduction in their chain length with potential ecological implications as, for instance, changes in diatom's chain buoyancy as well as the formation and sinking of aggregates (Bellingeri et al., 2020).

Concerning PS-NH$H_{2}$ NPs, Bergami et al. (2017) reported a significant growth inhibition in the unicellular green microalga D. tertiolecta $\left[\mathrm{EC}_{50}(72 \mathrm{~h})\right.$ of $\left.12.97 \mu \mathrm{g} \mathrm{ml} \mathrm{m}^{-1}\right]$, while Seoane et al. (2019) found no effect on growth of the marine diatom Chaetoceros neogracile. This discrepancy can be explained by the different sizes of PS- $\mathrm{NH}_{2}$ NPs (50 vs. $500 \mathrm{~nm}$ ) used in the two studies and their behavior in the algal media, whereas $50 \mathrm{~nm}$ of PS- $\mathrm{NH}_{2}$ NPs showed low aggregation and a positive surface charge (Bergami et al., 2017), $500 \mathrm{~nm}$ of PS- $\mathrm{NH}_{2}$ NPs agglomerated $(>3 \mu \mathrm{m})$ and resulted as negatively charged (Seoane et al., 2019). Different results in standard algal growth inhibition tests can also be related to the species sensitivity of phytoplankton toward nanoplastics. While marine diatoms are characterized by a silicified wall, green microalgae like D. tertiolecta present a thin cellular membrane (Oren, 2005), which may facilitate interactions with anthropogenic NPs with respect to other species.

Ecotoxicity studies on zooplankton mainly investigated the potential accumulation of PS NPs in the digestive tract of model organisms, by the detection of fluorescently labeled NPs under optical fluorescent or confocal microscopy through the thin transparent body of copepods (Lee et al., 2013; Jeong et al., 2017), anostracans (Bergami et al., 2016), rotifers (Snell and Hicks, 2009; Jeong et al., 2016, 2018; Manfra et al., 2017), and other planktonic larvae (Cole and Galloway, 2015; Della Torre et al., 2015b; Gambardella et al., 2017, 2018). Although egestion of large PS agglomerates, incorporated in fecal pellet structure, has been observed in several planktonic species (Lee et al., 2013; Bergami et al., 2016, 2017), some studies showed that PS NPs were still retained in the digestive tract of the exposed organisms after a 24-h recovery period (Bergami et al., 2016; Jeong et al., 2017; Manfra et al., 2017) and were removed less efficiently compared to micro-sized particles (Jeong et al., 2016). Plain PS and negatively charged PS-COOH NPs normally did not provoke mortality after acute (Della Torre et al., 2014; Cole and Galloway, 2015; Bergami et al., 2016; Gambardella et al., 2017; Manfra et al., 2017) or long-term (Bergami et al., 2017) exposures, although several sub-lethal effects have been reported, from the alteration in the swimming activity (Gambardella et al., 2017) to the decrease in fecundity, reproduction efficiency, and offspring fitness (Lee et al., 2013; Jeong et al., 2016, 2017). A concentration-dependent toxicity on growth and reproduction has been reported in the rotifer Brachionus spp., with a negative correlation between toxicity and NP size (Snell and Hicks, 2009; Jeong et al., 2016). In both studies, 50-nm PS NPs caused the most deleterious effects compared to larger NPs $(100-500 \mathrm{~nm})$ and microplastics $(6 \mu \mathrm{m})$.

Some studies also reported the induction of oxidative stress (Jeong et al., 2016; González-Fernández et al., 2018) as well as mantle and shell malformations in the oyster C. gigas D-larvae following exposure to plain PS and PS-COOH NPs (Tallec et al., 2018).

In general, a higher toxicity in the marine zooplankton was associated to positively charged PS- $\mathrm{NH}_{2} \mathrm{NPs}$, with average $\mathrm{EC}_{50}$ values ranging from $0.14 \mu \mathrm{g} \mathrm{ml}^{-1}$ in the mussel M. galloprovincialis (Balbi et al., 2017) and $0.15 \mu \mathrm{g} \mathrm{ml}^{-1}$ in the oyster C. gigas D-larva (Tallec et al., 2018), to $2.61 \mu \mathrm{g}$ $\mathrm{ml}^{-1}$ in the sea urchin P. lividus pluteus (Della Torre et al., 2014) and $6.62 \mu \mathrm{g} \mathrm{ml}^{-1}$ in the rotifer B. plicatilis larva (Manfra et al., 2017). In Artemia spp. PS- $\mathrm{NH}_{2}$ NPs provoked significant physiological alterations in the exposed larvae, including multiple molting (Bergami et al., 2016, 2017) as well as oxidative stress and neurotoxicity over short- and long-term exposure, as indicated by the significant decrease in the cholinesterase activity (Varó et al., 2019), leading to mortality after 14 days (Bergami et al., 2017; Varó et al., 2019). Long-term endpoints appeared thus more suitable to assess the toxicity of PS NPs to marine zooplankton (Lee et al., 2013; Bergami et al., 2017; Varó et al., 2019).

Marine mussels belonging to the Mytilus genus have been largely adopted as model organisms to investigate the biological effects of PS NPs through laboratory studies. Following shortterm in vivo experiments (up to $72 \mathrm{~h}$ ), ingestion and egestion of PS NP agglomerates have been confirmed in suspensionfeeding bivalves (Ward and Kach, 2009), with the organisms starting to internalize NPs already in the first hour of exposure (Farrell and Nelson, 2013). In the mussel M. edulis, this has been associated with the production of pseudofeces (Wegner et al., 2012; Farrell and Nelson, 2013) and a reduced filtering activity, following exposure to high concentrations (up to $300 \mu \mathrm{g} \mathrm{ml}^{-1}$ ) of sulfate-functionalized PS NPs (Wegner et al., 2012). Furthermore, trophic transfer of plain PS NPs of different sizes (30,100, and $500 \mathrm{~nm}$ ) from mussels to the crab Carcinus maenas has been demonstrated under laboratory conditions (Farrell and Nelson, 2013). Some studies reported the ability of PS NPs to translocate from the hemolymph to target tissues in benthic invertebrates (Farrell and Nelson, 2013) in a size-dependent manner, with $50 \mathrm{~nm}$ of PS NPs more internalized by hemocytes than larger particles (Sendra et al., 2019a), taken up in immune cells, and cause oxidative stress, immunotoxicity, and genotoxicity (Canesi et al., 2015; Brandts et al., 2018; Bergami et al., 2019; Ciacci et al., 2019; Sendra et al., 2019a). In a recent study on the benthic foraminifer Ammonia parkinsoniana, plain PS NPs tested at a concentration of $1 \mu \mathrm{g} \mathrm{ml}^{-1}$ were internalized in the single-cell marine eukaryotes within $24 \mathrm{~h}$, enhancing freeradical production and accumulation of intracellular neutral lipids (Ciacci et al., 2019). Furthermore, one study available on the Antarctic sea urchin Sterechinus neumayeri (Bergami et al., 2019) reported the sensitivity of this polar benthic 
species to anthropogenic NPs, by investigating the effects of two functionalized PS NPs (at 1 and $5 \mu \mathrm{g} \mathrm{ml}^{-1}$ ) on sea urchin coelomocytes following in vitro short-term exposure. PS-COOH NPs were able to induce an inflammatory response, with the modulation of genes having a role against oxidative stress and apoptosis, while a toxicity threshold was likely reached for PS$\mathrm{NH}_{2} \mathrm{NPs}$ under the same experimental conditions.

For marine vertebrates, several studies have been conducted on freshwater species, in particular, on the zebrafish Danio rerio (as reviewed in Chae and An, 2017), while little information is available on marine model organisms. Yin et al. (2019) evaluated the alteration in behavior and metabolism of a marine demersal fish (Sebastes schlegelii) exposed to $190 \mu \mathrm{g} \mathrm{L}^{-1}$ of PS NPs (nominal size of $500 \mathrm{~nm}$ ) for 14 days. A significant decrease in protein and lipid content was observed, potentially associated with reduced fish energy reserve and altered feeding behavior. However, the negative impact appeared limited compared to the effects of larger micro-sized PS (15 $\mu \mathrm{m})$. Almeida et al. (2019) reported that $100 \mathrm{~nm}$ of PS NPs was not cytotoxic to cell lines of two marine fish (Sparus aurata and D. labrax) after in vitro exposure $(24 \mathrm{~h})$, though they altered the lethality of human pharmaceuticals.

\section{CURRENT GAPS AND FUTURE RECOMMENDATION}

A comprehensive review of the major findings regarding the behavior, interactions with biological surfaces, and effects of $\mathrm{TiO}_{2}$ and PS NPs in the marine environment is reported. Although several behavior patterns have been defined as well as major impacts and toxicity mechanisms determined on key marine species, some knowledge gaps remain and shape the future studies on this growing research field. The detection of anthropogenic NPs at trace levels in natural systems, such as seawater and sediments, remains the greatest challenge to monitor them in the marine environment and hone the probabilistic NP flow modeling (Sun et al., 2016). Analytical methods, such as stable isotope tracer and liquid chromatography coupled to high-resolution mass spectrometry, should be adapted and further implemented for anthropogenic NPs.

Future laboratory experiments should be carried out at environmentally realistic concentrations (i.e., $<\mu \mathrm{g} \mathrm{L}^{-1}$ ), for example using metal-doped nanoplastics (Koelmans, 2019;

\section{REFERENCES}

Adeleye, A. S., Conway, J. R., Perez, T., Rutten, P., and Keller, A. A. (2014). Influence of extracellular polymeric substances on the long-term fate, dissolution, and speciation of copper-based nanoparticles. Environ. Sci. Technol. 48, 12561-12568. doi: 10.1021/es5033426

Adeleye, A. S., and Keller, A. A. (2014). Long-term colloidal stability and metal leaching of single wall carbon nanotubes: effect of temperature and extracellular polymeric substances. Wat. Res. 49, 236-250. doi: 10.1016/j.watres.2013.11.032

Albanese, A., Tang, P. S., and Chan, W. C. W. (2012). The effect of nanoparticle size, shape, and surface chemistry on biological systems. Annu. Rev. Biomed. Eng. 14, 1-16. doi: 10.1146/annurev-bioeng-071811-150124
Mitrano et al., 2019) or radio-labeled NPs (Bourgeault et al., 2015; Al-Sid-Cheikh et al., 2018) that can be traced both in complex matrices and the biota, allowing for a more reliable environmental risk assessment. In an ecological perspective, long-term and chronic endpoints should be preferred over acute standard ecotoxicity tests, and multi-species studies are encouraged to understand the impacts of anthropogenic NPs over key ecological processes, such as algal bloom formation and particulate organic carbon flux. "Omics" approaches are promising tools to determine signaling cascade and toxicity mechanisms triggered by anthropogenic NPs in biological systems. Finally, gaining knowledge on the bio- and ecocorona(s) formation will be crucial to unveil the complex nanobio interactions occurring in natural systems. Their study and consideration in the framework of ecotoxicity studies is of paramount importance to obtain meaningful outcomes and to extend to them real environmental scenarios.

\section{AUTHOR CONTRIBUTIONS}

IC conceived the outline of the review, and drafted the manuscript for the introduction and $\mathrm{TiO}_{2}$ ecotoxicity state of the art. EB drafted the manuscript for the introduction, the behavior paragraph, and PS ecotoxicity state of the art. GG drafted the manuscript for the corona concept paragraph. All authors contributed to improving the manuscript and approved the submission.

\section{FUNDING}

This work was partly supported by the following funded projects: Plastics in Antarctic Environment (PLANET) and Polymeric nanoparticles in the marine environment and in Antarctic organisms (NANOPANTA), both funded by the Italian National Antarctic Program (PNRA: 14_00090; 16_00075).

\section{SUPPLEMENTARY MATERIAL}

The Supplementary Material for this article can be found online at: https://www.frontiersin.org/articles/10.3389/fenvs. 2020.00060/full\#supplementary-material

Alijagic, A., Benada, O., Kofroňová, O., Cigna, D., and Pinsino, A. (2019). Sea urchin extracellular proteins design a complex protein corona on titanium dioxide nanoparticle surface influencing immune cell behavior. Front. Immunol. 10:2261. doi: 10.3389/fimmu.2019.02261

Alijagic, A., Gaglio, D., Napodano, E., Russo, R., Costa, C., Benada, O., et al. (2020). Titanium dioxide nanoparticles temporarily influence the sea urchin immunological state suppressing inflammatory-relate gene transcription and boosting antioxidant metabolic activity. J. Hazard. Mater. 384:389. doi: 10.1016/ j.jhazmat.2019.121389

Alijagic, A., and Pinsino, A. (2017). Probing safety of nanoparticles by outlining sea urchin sensing and signaling cascades. Ecotoxicol. Environ. Saf. 144, 416-421. doi: 10.1016/j.ecoenv.2017.06.060 
Almeida, M., Martins, M. A., Soares, A. M. V., Cuesta, A., and Oliveira, M. (2019). Polystyrene nanoplastics alter the cytotoxicity of human pharmaceuticals on marine fish cell lines. Environ. Toxicol. Pharmacol. 69, 57-65. doi: 10.1016/j. etap.2019.03.019

Al-Sid-Cheikh, M., Rowland, S. J., Stevenson, K., Rouleau, C., Henry, T. B., and Thompson, R. C. (2018). Uptake, whole-body distribution, and depuration of nanoplastics by the scallop pecten maximus at environmentally realistic concentrations. Environ. Sci. Technol. 52, 14480-14486. doi: 10.1021/acs.est. 8 b05266

Andrady, A. L. (2017). The plastic in microplastics: a review. Mar. Pollut. Bull. 119, 12-22. doi: 10.1016/j.marpolbul.2017.01.082

Auguste, M., Balbi, T., Montagna, M., Fabbri, R., Sendra, M., Blasco, J., et al. (2019). In vivo immunomodulatory and antioxidant properties of nanoceria ( $\mathrm{nCeO} 2$ ) in the marine mussel Mytilus galloprovincialis. Comp. Biochem. Physiol. Part C Toxicol. Pharmacol. 219, 95-102. doi: 10.1016/j.cbpc.2019.02.006

Baalousha, M. (2017). Effect of nanomaterial and media physicochemical properties on nanomaterial aggregation kinetics. Nanoimpact 6, 55-68. doi: 10.1016/j.impact.2016.10.005

Baalousha, M., Cornelis, G., Kuhlbusch, T. A. J., Lynch, I., Nickel, C., Peijnenburg, W., et al. (2016). Modeling nanomaterial fate and uptake in the environment: current knowledge and future trends. Environ. Sci. Nano 3, 323-345. doi: 10. 1039/c5en00207a

Balbi, T., Camisassi, G., Montagna, M., Fabbri, R., Franzellitti, S., Carbone, C., et al. (2017). Impact of cationic polystyrene nanoparticles (PS-NH2) on early embryo development of Mytilus galloprovincialis: effects on shell formation. Chemosphere 186, 1-9. doi: 10.1016/j.chemosphere.2017.07.120

Balbi, T., Smerilli, A., Fabbri, R., Ciacci, C., Montagna, M., Grasselli, E., et al. (2014). Co-exposure to $\mathrm{n}$-TiO2and $\mathrm{Cd} 2+$ results in interactive effects on biomarker responses but not in increased toxicity in the marine bivalve M. galloprovincialis. Sci. Tot. Environ. 493, 355-364. doi: 10.1016/j.scitotenv. 2014.05.146

Banni, M., Sforzini, S., Balbi, T., Corsi, I., Viarengo, A., and Canesi, L. (2016). Combined effectsof $\mathrm{n}-\mathrm{TiO} 2$ and 2,3,7,8-TCDD in Mytilus galloprovincialis digestive gland: a transcriptomic and immunohistochemical study. Environ. Res. 145, 135-144. doi: 10.1016/j.envres.2015.12.003

Baudrimont, M., Arini, A., Guégan, C., Venel, Z., Gigault, J., Pedrono, B., et al. (2019). Ecotoxicity of polyethylene nanoplastics from the North Atlantic oceanic gyre on freshwater and marine organisms (microalgae and filter-feeding bivalves). Environ. Sci. Pollut. Res. 27, 3746-3755. doi: 10.1007/s11356-01904668-3

Bellingeri, A., Casabianca, S., Cappellacci, S., Faleri, C., Paccagnigi, E., Lupetti, P., et al. (2020). Impact of polystyrene nanoparticles on marine diatom Skeletonema marinoi chain assemblages and consequences on their ecological role in marine ecosystems. Environ. Pollut. 262:114268. doi: 10.1016/j.envpol. 2020.114268

Beninger, P. G., and St-Jean, S. D. (1997). The role of mucus in particle processing by suspension-feeding marine bivalves: unifying principles. Mar. Biol. 129, 389-397. doi: 10.1007/s002270050179

Bergami, E., Bocci, E., Vannuccini, M. L., Monopoli, M., Salvati, A., Dawson, K. A., et al. (2016). Nano-sized polystyrene affects feeding, behavior and physiology of brine shrimp Artemia franciscana larvae. Ecotoxicol. Environ. Saf. 123, 18-25. doi: 10.1016/j.ecoenv.2015.09.021

Bergami, E., Krupinski Emerenciano, A., González-Aravena, M., Cárdenas, C. A., Hernández, P., Silva, J. R. M. C., et al. (2019). Polystyrene nanoparticles affect the innate immune system of the Antarctic sea urchin Sterechinus neumayeri. Polar Biol. 42, 743-757. doi: 10.1007/s00300-019-02468-6

Bergami, E., Pugnalini, S., Vannuccini, M. L., Manfra, L., Faleri, C., Savorelli, F., et al. (2017). Long-term toxicity of surface-charged polystyrene nanoplastics to marine planktonic species Dunaliella tertiolecta and Artemia franciscana. Aquat. Toxicol. 189, 159-169. doi: 10.1016/j.aquatox.2017. 06.008

Bexiga, M. G., Kelly, C., Dawson, K. A., and Simpson, J. C. (2014). RNAi-mediated inhibition of apoptosis fails to prevent cationic nanoparticle-induced cell death in cultured cells. Nanomedicine 9, 1651-1664. doi: 10.2217/nnm.13.151

Bexiga, M. G., Varela, J. A., Wang, F., Fenaroli, F., Salvati, A., Lynch, I., et al. (2011). Cationic nanoparticles induce caspase 3-, 7-and 9-mediated cytotoxicity in a human astrocytoma cell line. Nanotoxicology 5, 557-567. doi: 10.3109/ 17435390.2010 .539713
Bhargava, S., Chen Lee, S. S., Min Ying, L. S., Neo, M. L., Lay-Ming Teo, S., and Valiyaveettil, S. (2018). Fate of nanoplastics in marine larvae: a case study using barnacles, Amphibalanus amphitrite. ACS Sustain. Chem. Eng. 6, 6932-6940. doi: 10.1021/acssuschemeng.8b00766

Bhuvaneshwari, M., Sagar, B., Doshi, S., Chandrasekaran, N., and Mukherjee, A. (2017). Comparative study on toxicity of $\mathrm{ZnO}$ and $\mathrm{TiO} 2$ nanoparticles on Artemia salina: effect of pre-UV-A and visible light irradiation. Environ. Sci. Pollut. Res. 24, 5633-5646. doi: 10.1007/s11356-016-8328-z

Bhuvaneshwari, M., Thiagarajan, V., Nemade, P., Chandrasekaran, N., and Mukherjee, A. (2018). Toxicity and trophic transfer of P25 TiO2 NPs from Dunaliella salina to Artemia salina: effect of dietary and waterborne exposure. Environ. Res. 160, 39-46. doi: 10.1016/j.envres.2017.09.022

Blair, R. M., Waldron, S., Phoenix, V., and Gauchotte-Lindsay, C. (2017). Microand nanoplastic pollution of freshwater and wastewater treatment systems. Springer Sci. Rev. 5, 19-30. doi: 10.1007/s40362-017-0044-7

Blasco, J., Corsi, I., and Matranga, V. (2015). Particles in the ocean, implications for a safe marine environment. Mar. Environ. Res. 111, 1-4. doi: 10.1016/j. marenvres.2015.10.001

Botta, C., Labille, J., Auffan, M., Bornscheck, D., Miche, H., Cabié, M., et al. (2011). $\mathrm{TiO} 2$-based nanoparticles released in water from commercialized sunscreeens in a life-cycle perspective: structures and quantities. Environ. Poll. 159, 15431550. doi: 10.1016/j.envpol.2011.03.003

Bourgeault, A., Cousin, C., Geertsen, V., Cassier-Chauvat, C., Chauvat, F., Durupthy, O., et al. (2015). The challenge of studying $\mathrm{TiO} 2$ nanoparticle bioaccumulation at environmental concentrations: crucial use of a stable isotope tracer. Environ. Sci. Technol. 49, 2451-2459. doi: 10.1021/es504638f

Bourgeault, A., Legros, V., Gonnet, F., Daniel, R., Paquirissamy, A., Bénatar, C., et al. (2017). Interaction of $\mathrm{TiO} 2$ nanoparticles with proteins from aquatic organisms: the case of gill mucus from blue mussel. Environ. Sci. Pollut. Res. 24, 13474-13483. doi: 10.1007/s11356-017-8801-3

Bourikas, K., Hiemstra, T., and Van Riemsdijk, W. H. (2001). Ion pair formation and primary charging behavior of titanium oxide (anatase and rutile). Langmuir 17, 749-756. doi: 10.1021/la000806c

Brandts, I., Teles, M., Gonçalves, A. P., Barreto, A., Franco-Martinez, L., Tvarijonaviciute, A., et al. (2018). Effects of nanoplastics on Mytilus galloprovincialis after individual and combined exposure with carbamazepine. Sci. Total Environ. 643, 775-784. doi: 10.1016/j.scitotenv.2018.06.257

Brunelli, A., Poiana, G., Callegaro, S., and Marcomini, A. (2013). Agglomeration and sedimentation of titanium dioxide nanoparticles (n-TiO2) in synthetic and realwaters. J. Nanopart. Res. 15, 1-10. doi: 10.1007/s11051-013-1684-4

Budarz, J. F., Turolla, A., Piasecki, A. F., Bottero, J., Antonelli, M., and Wiesner, M. R. (2017). Influence of aqueous inorganic anions on the reactivity of nanoparticles in TiO2 photocatalysis. Langmuir 33, 2770-2779. doi: 10.1021/ acs.langmuir.6b04116

Cai, L., Hu, L., Shi, H., Ye, J., Zhang, Y., and Kim, H. (2018). Effects of inorganic ions and natural organic matter on the aggregation of nanoplastics. Chemosphere 197, 142-151. doi: 10.1016/j.chemosphere.2018.01.052

Canesi, L., Auguste, M., and Bebianno, M. J. (2019). "Sublethal effects of nanoparticles in aquatic invertebrates, from molecular to organism level," in Ecotoxicology of Nanoparticles in Aquatic Systems, eds J. Blasco and I. Corsi (Milton Park: CRC Taylor \& Francis Group), 38-61. doi: 10.1201/ 9781315158761-2

Canesi, L., Balbi, T., Fabbri, R., Salis, A., Damonte, G., Volland, M., et al. (2017). Biomolecular coronas in invertebrate species: implications in the environmental impact of nanoparticles. NanoImpact 8, 89-98. doi: 10.1016/j. impact.2017.08.001

Canesi, L., Ciacci, C., and Balbi, T. (2016a). Invertebrate models for investigating the impact of nanomaterials on innate immunity: the example of the marine mussel Mytilus spp. Curr. Bionanotechnol. 2, 77-83. doi: 10.2174/ 2213529402666160601102529

Canesi, L., Ciacci, C., Fabbri, R., Balbi, T., Salis, A., Damonte, G., et al. (2016b). Interactions of cationic polystyrene nanoparticles with marine bivalve hemocytes in a physiological environment: role of soluble hemolymph proteins. Environ. Res. 150, 73-81. doi: 10.1016/j.envres.2016.05.045

Canesi, L., Ciacci, C., Bergami, E., Monopoli, M. P., Dawson, K. A., Papa, S., et al. (2015). Evidence for immunomodulation and apoptotic processes induced by cationic polystyrene nanoparticles in the hemocytes of the marine bivalve Mytilus. Mar. Environ. Res. 111, 34-40. doi: 10.1016/j.marenvres.2015.06.008 
Canesi, L., and Corsi, I. (2016). Effects of nanomaterials on marine invertebrates. Sci. Total Environ. 565, 933-940. doi: 10.1016/j.scitotenv.2016.01.085

Canesi, L., Frenzilli, G., Balbi, T., Bernardeschi, M., Ciacci, C., Corsolini, S., et al. (2014). Interactive effects on $\mathrm{n}-\mathrm{TiO} 2$ and 2,3,7,8-TCDD on the marine bivalve Mytilus galloprovincialis. Aquat. Toxicol. 153, 53-65. doi: 10.1016/j.aquatox. 2013.11.002

Caracciolo, G., Pozzi, D., Capriotti, A. L., Cavaliere, C., Foglia, P., Amenitsch, H., et al. (2011). Evolution of the protein corona of lipid gene vectors as a function of plasma concentration. Langmuir 27, 15048-15053. doi: 10.1021/la202912f

Cardellini, A., Alberghini, M., Govind Rajan, A., Misra, R. P., Blankschtein, D., and Asinari, P. (2019). Multi-scale approach for modeling stability, aggregation, and network formation of nanoparticles suspended in aqueous solutions. Nanoscale 11, 3925-3932. doi: 10.1039/c8nr08782b

Carp, O., Huisman, C. L., and Reller, A. (2004). Photoinduced reactivity of titanium dioxide. Prog. Solid State Chem. 32, 33-77.

Casals, E., Pfaller, T., Duschl, A., Oostingh, G. J., and Puntes, V. (2010). Time evolution of the nanoparticle protein corona. ACS Nano 4, 3623-3632. doi: $10.1021 / \mathrm{nn} 901372 \mathrm{t}$

Cedervall, T., Lynch, I., Foy, M., Berggård, T., Donnelly, S. C., Cagney, G., et al. (2007a). Detailed identification of plasma proteins adsorbed on copolymer nanoparticles. Angew. Chemie Int. Ed. 46, 5754-5756. doi: 10.1002/anie. 200700465

Cedervall, T., Lynch, I., Lindman, S., Berggard, T., Thulin, E., Nilsson, H., et al. (2007b). Understanding the nanoparticle-protein corona using methods to quantify exchange rates and affinities of proteins for nanoparticles. Proc. Natl. Acad. Sci. U.S.A. 104, 2050-2055. doi: 10.1073/pnas.0608582104

Chae, Y., and An, Y. J. (2017). Effects of micro- and nanoplastics on aquatic ecosystems: current research trends and perspectives. Mar. Pollut. Bull. 124, 624-632. doi: 10.1016/j.marpolbul.2017.01.070

Chen, C. S., Anaya, J. M., Zhang, S., Spurgin, J., Chuang, C. Y., Xu, C., et al. (2011). Effects of engineered nanoparticles on the assembly of exopolymeric substances from phytoplankton. PLoS One 6:e21865. doi: 10.1371/journal.pone.0021865

Chen, C. S., Le, C., Chiu, M. H., and Chin, W. C. (2018). The impact of nanoplastics on marine dissolved organic matter assembly. Sci. Total Environ. 634, 316-320. doi: 10.1016/j.scitotenv.2018.03.269

Choi, S., Johnston, M., Wang, G.-S., and Huang, C. P. (2018). A seasonal observation on the distribution of engineered nanoparticles in municipal wastewater treatment systems exemplified by $\mathrm{TiO} 2$ and $\mathrm{ZnO}$. Sci. Tot. Environ. 625, 1321-1329. doi: 10.1016/j.scitotenv.2017.12.326

Chong, M. N., Jin, B., Chow, C. W. K., and Saint, C. (2010). Recent developments in photocatalytic water treatment technology: a review. Water Res. 44, 2997-3027. doi: 10.1016/j.watres.2010.02.039

Ciacci, C., Grimmelpont, M. V., Corsi, I., Bergami, E., Curzi, D., Burini, D., et al. (2019). Nanoparticle-biological interactions in a marine benthic foraminifer. Sci. Rep. 9:19441. doi: 10.1038/s41598-019-56037-2

Cole, M., and Galloway, T. S. (2015). Ingestion of nanoplastics and microplastics by pacific oyster larvae. Environ. Sci. Technol. 49, 14625-14632. doi: 10.1021/ acs.est.5b04099

Corinaldesi, C., Marcellini, F., Nepote, E., Damiani, E., and Danovaro, R. (2018). Impact of inorganic UV filters contained in sunscreen products on tropical stony corals (Acropora spp.). Sci. Tot. Environ. 637-638, 1279-1285. doi: 10. 1016/j.scitotenv.2018.05.108

Corsi, I., Cherr, G. N., Lenihan, H. S., Labille, J., Hassellov, M., Canesi, L., et al. (2014). Common strategies and technologies for the ecosafety assessment and design of nanomaterials entering the marine environment. ACS Nano 8, 9694-9709. doi: 10.1021/nn504684k

Corsi, I., Winther-Nielsen, M., Sethi, R., Punta, C., Della Torre, C., Libralato, G., et al. (2018). Ecofriendly nanotechnologies and nanomaterials for environmental applications: key issue and consensus recommendations for sustainable and ecosafe nanoremediation. Ecotox. Environ. Saf. 154, 237-244. doi: 10.1016/j.ecoenv.2018.02.037

Cózar, A., Echevarría, F., González-Gordillo, J. I., Irigoien, X., Úbeda, B., Hernández-León, S., et al. (2014). Plastic debris in the open ocean. Proc. Natl. Acad. Sci. U.S.A. 111, 10239-10244. doi: 10.1073/pnas.1314705111

da Silva, B. F., Pérez, S., Gardinalli, P., Singhal, R. K., Mozeto, A. A., and Barceló, D. (2011). Analytical chemistry of metallic nanoparticles in natural environments. TrAC Trends Anal. Chem. 30, 528-540. doi: 10.1016/j.trac.2011.01.008
Danielsson, K., Persson, P., Gallego-Urrea, J. A., Abbas, Z., Rosenqvist, J., and Jonsson, C. M. (2018). Effects of the adsorption of NOM model molecules on the aggregation of $\mathrm{TiO} 2$ nanoparticles in aqueous suspensions. Nanoimpact 10 , 177-187. doi: 10.1016/j.impact.2018.05.002

Davidson, T. M. (2012). Boring crustaceans damage polystyrene floats under docks polluting marine waters with microplastic. Mar. Pollut. Bull. 64, 1821-1828. doi: 10.1016/j.marpolbul.2012.06.005

Della Torre, C., Balbi, T., Grassi, G., Frenzilli, G., Bernardeschi, M., Smerilli, A., et al. (2015a). Titanium dioxide nanoparticles modulate the toxicological response to cadmium in the gills of Mytilus galloprovincialis. J. Haz. Mat. 297, 92-100. doi: 10.1016/j.jhazmat.2015.04.072

Della Torre, C., Bergami, E., Salvati, A., Faleri, C., Cirino, P., Dawson, K. A., et al. (2014). Accumulation and embryotoxicity of polystyrene nanoparticles at early stage of development of sea urchin embryos Paracentrotus lividus. Environ. Sci. Technol. 48, 12302-12311. doi: 10.1021/es502569w

Della Torre, C., Buonocore, F., Frenzilli, G., Corsolini, S., Brunelli, A., Guidi, P., et al. (2015b). Influence of titanium dioxide nanoparticles on 2,3,7,8tetrachlorodibenzo- $p$-dioxin bioconcentration and toxicity in the marine fish european sea bass (Dicentrachus labrax). Environ. Pollut. 196, 185-193. doi: 10.1016/j.envpol.2014.09.020

Deng, X. Y., Cheng, J., Hu, X. L., Wang, L., Li, D., and Gao, K. (2017). Biological effects of $\mathrm{TiO} 2$ and $\mathrm{CeO} 2$ nanoparticles on the growth, photosynthetic activity, and cellular components of a marine diatom Phaeodactylum tricornutum. Sci. Total Environ. 575, 87-96. doi: 10.1016/j.scitotenv.2016.10.003

Dobrovolskaia, M. A., Patri, A. K., Zheng, J., Clogston, J. D., Ayub, N., Aggarwal, P., et al. (2009). Interaction of colloidal gold nanoparticles with human blood: effects on particle size and analysis of plasma protein binding profiles. Nanomed. Nanotechnol. Biol. Med. 5, 106-117. doi: 10.1016/j.nano.2008.08.001

Docter, D., Westmeier, D., Markiewicz, M., Stolte, S., Knauer, S. K., and Stauber, R. H. (2015). The nanoparticle biomolecule corona: lessons learned - challenge accepted? Chem. Soc. Rev. 44, 6094-6121. doi: 10.1039/C5CS00217F

Doyle, J. J., Ward, E. J., and Mason, R. (2015). An examination of the ingestion, bioaccumulation, and depuration of titanium dioxide nanoparticles by the blue mussel (Mytilus edulis) and the eastern oyster (Crassostrea virginica). Mar. Environ. Res. 110, 45-52. doi: 10.1016/j.marenvres.2015.07.020

Eigenheer, R., Castellanos, E. R., Nakamoto, M. Y., Gerner, K. T., Lampe, A. M., and Wheeler, K. E. (2014). Silver nanoparticle protein corona composition compared across engineered particle properties and environmentally relevant reaction conditions. Environ. Sci. Nano 1:238. doi: 10.1039/c4en00002a

Espinosa, E. P., Hassan, D., Ward, J. E., Shumway, S. E., and Allam, B. (2010). Role of epicellular molecules in the selection of particles by the blue mussel, Mytilus edulis. Biol. Bull. 219, 50-60. doi: 10.1086/bblv219n1p50

European Commission [EU] (2011). European commission. 2011/696/EU commission recommendation of 18 October 2011 on the definition of nanomaterial. Off. J. Eur. Union 54:38.

Falugi, C., Aluigi, M. G., Chiantore, M. C., Privitera, D., Ramoino, P., Gatti, M. A., et al. (2012). Toxicity of metal oxide nanoparticles in immune cells of the sea urchin. Mar. Environ. Res. 76, 114-121. doi: 10.1016/j.marenvres.2011. 10.003

Farkas, J., Bergum, S., Nilsen, E. W., Olsen, A. J., Salaberria, I., Ciesielski, T. M., et al. (2015). The impact of $\mathrm{TiO} 2$ nanoparticles on uptake and toxicity of benzo(a)pyrene in the blue mussel (Mytilus edulis). Sci. Total Environ. 511, 469-476. doi: 10.1016/j.scitotenv.2014.12.084

Farrell, P., and Nelson, K. (2013). Trophic level transfer of microplastic: Mytilus edulis (L.) to Carcinus maenas (L.). Environ. Pollut. 177, 1-3. doi: 10.1016/j. envpol.2013.01.046

Fotopoulou, K. N., and Karapanagioti, H. K. (2012). Surface properties of beached plastic pellets. Mar. Environ. Res. 81, 70-77. doi: 10.1016/j.marenvres.2012. 08.010

French, R. A., Jacobson, A. R., Kim, B., Isley, S. L., Penn, L., and Baveye, P. C. (2009). Influence of ionic strength, $\mathrm{pH}$, and cation valence on aggregation kinetics of titanium dioxide nanoparticles. Environ. Sci. Technol. 43, 1354-1359. doi: 10.1021/es802628n doi: 10.1021/es802628n

Fröhlich, E., Meindl, C., Roblegg, E., Ebner, B., Absenger, M., and Pieber, T. R. (2012). Action of polystyrene nanoparticles of different sizes on lysosomal function and integrity. Part. Fibre Toxicol. 9:1. doi: 10.1186/1743-8977 $-9-26$ 
Fu, S. F., Ding, J. N., Zhang, Y., Li, Y. F., Zhu, R., Yuan, X. Z., et al. (2018). Exposure to polystyrene nanoplastic leads to inhibition of anaerobic digestion system. Sci. Total Environ. 625, 64-70. doi: 10.1016/j.scitotenv.2017.12.158

Gambardella, C., Morgana, S., Bramini, M., Rotini, A., Manfra, L., Migliore, L., et al. (2018). Ecotoxicological effects of polystyrene microbeads in a battery of marine organisms belonging to different trophic levels. Mar. Environ. Res. 141, 313-321. doi: 10.1016/j.marenvres.2018.09.023

Gambardella, C., Morgana, S., Ferrando, S., Bramini, M., Piazza, V., Costa, E., et al. (2017). Effects of polystyrene microbeads in marine planktonic crustaceans. Ecotoxicol. Environ. Saf. 145, 250-257. doi: 10.1016/j.ecoenv.2017.07.036

Gao, J., Lin, L., Wei, A., and Sepúlveda, M. S. (2017). Protein corona analysis of silver nanoparticles exposed to fish plasma. Environ. Sci. Technol. Lett. 4, 174-179. doi: 10.1021/acs.estlett.7b00074

García-Álvarez, R., Hadjidemetriou, M., Sánchez-Iglesias, A., Liz-Marzán, L. M., and Kostarelos, K. (2018). In vivo formation of protein corona on gold nanoparticles. the effect of their size and shape. Nanoscale 10, 1256-1264. doi: $10.1039 / \mathrm{c} 7 \mathrm{nr} 08322 \mathrm{j}$

Garner, K. L., Suh, S., and Keller, A. A. (2017). Assessing the risk of engineered nanomaterials in the environment: development and application of the nanofate model. Environ. Sci. Technol. 51, 5541-5551. doi: 10.1021/acs.est. $6 \mathrm{~b} 05279$

Gigault, J., Pedrono, B., Maxit, B., and Ter Halle, A. (2016). Marine plastic litter: the unanalyzed nano-fraction. Environ. Sci. Nano 3, 346-350. doi: 10.1039/ c6en00008h

Gondikas, A. P., von der Kammer, F., Reed, R. B., Wagner, S., Ranville, J. F., et al. (2014). Release of $\mathrm{TiO} 2$ nanoparticles from sunscreens into surface waters: a one-year survey at the old Danube recreational Lake. Environ. Sci. Technol. 48, 5415-5422. doi: 10.1021/es405596y

González-Fernández, C., Tallec, K., Le Goïc, N., Lambert, C., Soudant, P., Huvet, A., et al. (2018). Cellular responses of Pacific oyster (Crassostrea gigas) gametes exposed in vitro to polystyrene nanoparticles. Chemosphere 208, 764-772. doi: 10.1016/j.chemosphere.2018.06.039

González-Fernández, C., Toullec, J., Lambert, C., Le Goïc, N., Seoane, M., Moriceau, B., et al. (2019). Do transparent exopolymeric particles (TEP)affect the toxicity of nanoplastics on Chaetoceros neogracile? Environ. Pollut. 250, 873-882. doi: 10.1016/j.envpol.2019. 04.093

Gottschalk, F., and Nowack, B. (2011). The release of engineered nanomaterials to the environment. J. Environ. Monitor. 13:1145. doi: 10.1039/c0em00547a

Gottschalk, F., Sun, T. Y., and Nowack, B. (2013). Environmental concentrations of engineered nanomaterials: review of modeling and analytical studies. Environ. Pollut. 181, 287-300. doi: 10.1016/j.envpol.2013. 06.003

Goy-López, S., Juárez, J., Alatorre-Meda, M., Casals, E., Puntes, V. F., Taboada, P., et al. (2012). Physicochemical characteristics of protein-NP bioconjugates: the role of particle curvature and solution conditions on human serum albumin conformation and fibrillogenesis inhibition. Langmuir 28, 9113-9126. doi: 10. $1021 / \mathrm{la} 300402 \mathrm{w}$

Grassi, G., Landi, C., Della Torre, C., Bergami, E., Bini, L., and Corsi, I. (2019). Proteomic profile of the hard corona of charged polystyrene nanoparticles exposed to sea urchin Paracentrotus lividus coelomic fluid highlights potential drivers of toxicity. Environ. Sci. Nano. 6, 2937-2947. doi: 10.1039/C9EN00 $824 \mathrm{~A}$

Grillo, R., Rosa, A. H., and Fraceto, L. F. (2015). Engineered nanoparticles and organic matter: a review of the state-of-the-art. Chemosphere 119, 608-619. doi: 10.1016/j.chemosphere.2014.07.049

Grimaldi, A. M., Belcari, P., Pagano, E., Cacialli, F., and Locatello, L. (2013). Immune responses of Octopus vulgaris (Mollusca: Cephalopoda) exposed to titanium dioxide nanoparticles. J. Exp. Mar. Bio. Ecol. 447, 123-127. doi: 10. 1016/j.jembe.2013.02.018

Guan, X., Shi, W., Zha, S., Rong, J., Su, W., and Liu, G. (2018). Neurotoxic impact of acute $\mathrm{TiO} 2$ nanoparticle exposure on a benthic marine bivalve mollusk, Tegillarca granosa. Aquat. Toxicol. 200, 241-246. doi: 10.1016/j.aquatox.2018. 05.011

Gupta, G. S., Kumar, A., Shanker, R., and Dhawan, A. (2016). Assessment of agglomeration, co-sedimentation and trophic transfer of titanium dioxide nanoparticles in a laboratory-scale predator-prey model system. Sci. Rep. 6, 1-13. doi: $10.1038 /$ srep 31422
Guterres, S. S., Alves, M. P., and Pohlmann, A. R. (2007). Polymeric nanoparticles, nanospheres and nanocapsules, for cutaneous applications. Drug Target Insights 2, 147-157. doi: 10.1177/117739280700200002

Gutierrez, T., Teske, A., Ziervogel, K., Passow, U., and Quigg, A. (2018). Editorial: microbial exopolymers: sources, chemico-physiological properties, and ecosystem effects in the marine environment. Front. Microbiol. 9:1822. doi: $10.3389 /$ fmicb. 2018.01822

Hartmann, N. B., Hüffer, T., Thompson, R. C., Hassellöv, M., Verschoor, A., Daugaard, A. E., et al. (2019). Are we speaking the same language? recommendations for a definition and categorization framework for plastic debris. Environ. Sci. Technol. 53, 1039-1047. doi: 10.1021/acs.est.8b05297

Hayashi, Y., Miclaus, T., Scavenius, C., Kwiatkowska, K., Sobota, A., Engelmann, P., et al. (2013). Species differences take shape at nanoparticles: protein corona made of the native repertoire assists cellular interaction. Environ. Sci. Technol. 47, 14367-14375. doi: 10.1021/es404132w

Haynes, V. N., Ward, J. E., Russell, B. J., and Agrios, A. G. (2017). Photocatalytic effects of titanium dioxide nanoparticles on aquatic organisms-current knowledge and suggestions for future research. Aquat. Toxicol. 185, 138-148. doi: 10.1016/j.aquatox.2017.02.012

He, X., Aker, W. G., Fu, P. P., and Hwang, H. (2015). Toxicity of engineered metal oxide nanomaterials mediated by nano-bio-eco-interactions: a review and perspective. Environ. Sci. Nano 2, 564-582. doi: 10.1039/C5EN00094G

He, X., Fu, P., Aker, W. G., and Hwang, H. M. (2018). Toxicity of engineered nanomaterials mediated by nano-bio-eco interactions. J. Environ. Sci. Heal. Part C Environ. Carcinog. Ecotoxicol. Rev. 36, 21-42. doi: 10.1080/10590501. 2017.1418793

Hernandez, L. M., Xu, E. G., Larsson, H. C. E., Tahara, R., Maisuria, V. B., and Tufenkji, N. (2019). Plastic teabags release billions of microparticles and nanoparticles into tea. Environ. Sci. Technol. 53, 12300-12310. doi: 10.1021/acs. est.9b02540

Hernandez, L. M., Youse, N., and Tufenkji, N. (2017). Are there nanoplastics in your personal care products? Cell 7, 280-285. doi: 10.1021/acs.estlett.7b00187

Hessler, C. M., Wu, M. Y., Xue, Z., Choi, H., and Seo, Y. (2012). The influence of capsular extracellular polymeric substances on the interaction between $\mathrm{TiO} 2$ nanoparticles and planktonic bacteria. Water Res. 46, 4687-4696. doi: 10.1016/ j.watres.2012.06.009

Hochella, M. F. Jr., Mogk, D. W., Ranville, J., Allen, I. C., Luther, G. W., Marr, L. C., et al. (2019). Natural, incidental, and engineered nanomaterials and their impacts on the Earth system. Science 363, 6434-8299. doi: 10.1126/science. aau8299

Holden, P. A., Gardea-Torresdey, J. L., Klaessig, F., Turco, R. F., Mortimer, M., Hund-Rinke, K., et al. (2016). Considerations of environmentally relevant test conditions for improved evaluation of ecological hazards of engineered nanomaterials. Environ. Sci. Technol. 50, 6124-6145. doi: 10.1021/acs.est. $6 \mathrm{~b} 00608$

Hu, J., Wang, J., Liu, S., Zhang, Z., Zhang, H., Cai, X., et al. (2018). Effect of TiO2 nanoparticle aggregation on marine microalgae Isochrysis galbana. J. Environ. Sci. 66:208. doi: 10.1016/j.jes.2017.05.026

Huvet, A., Paul-Pont, I., Fabioux, C., Lambert, C., Suquet, M., Thomas, Y., et al. (2016). Quantifying the smallest microplastics is the challenge for a comprehensive view of their environmental impacts. Proc. Natl. Acad. Sci. U.S.A. 113, E4123-E4124. doi: 10.1073/pnas.1607221113

ISO (2006). Water Quality - Marine Algal Growth Inhibition Test With Skeletonema Costatum and Phaeodactylum tricornutum, ISO/TC 147/SC 5 10253. London: ISO.

Jeong, C., Kang, H., Lee, Y. H., Kim, M., Lee, J., Seo, J. S., et al. (2018). Nanoplastic ingestion enhances toxicity of persistent organic pollutants (POPs) in the monogonont rotifer Brachionus koreanus via multixenobiotic resistance (MXR) disruption. Environ. Sci. Technol. 52, 11411-11418. doi: 10.1021/acs.est. $8 \mathrm{~b} 03211$

Jeong, C. B., Kang, H. M., Lee, M. C., Kim, D. H., Han, J., Hwang, D. S., et al. (2017). Adverse effects of microplastics and oxidative stress-induced MAPK/Nrf2 pathway-mediated defense mechanisms in the marine copepod Paracyclopina nana. Sci. Rep. 7, 1-11. doi: 10.1038/srep41323

Jeong, C. B., Won, E. J., Kang, H. M., Lee, M. C., Hwang, D. S., Hwang, U. K., et al. (2016). Microplastic size-dependent toxicity, oxidative stress induction, and p-JNK and p-p38 activation in the monogonont rotifer (Brachionus koreanus). Environ. Sci. Technol. 50, 8849-8857. doi: 10.1021/acs.est.6b01441 
Jiménez-Fernández, E., Ruyra, A., Roher, N., Zuasti, E., Infante, C., and FernándezDíaz, C. (2014). Nanoparticles as a novel delivery system for vitamin C administration in aquaculture. Aquaculture 432, 426-433. doi: 10.1016/j. aquaculture.2014.03.006

Johnston, H. J., Semmler-Behnke, M., Brown, D. M., Kreyling, W., Tran, L., and Stone, V. (2010). Evaluating the uptake and intracellular fate of polystyrene nanoparticles by primary and hepatocyte cell lines in vitro. Toxicol. Appl. Pharmacol. 242, 66-78. doi: 10.1016/j.taap.2009.09.015

Jovanović, B., and Guzmán, H. M. (2014). Effects of titanium dioxide (TiO2) nanoparticles on caribbean reef-building coral (Montastraea faveolata). Environ. Toxicol. Chem. 33, 1346-1353. doi: 10.1002/etc.2560

Kadar, E., Cunliffe, M., Fisher, A., Stolpe, B., Lead, J., and Shi, Z. (2014). Chemical interaction of atmospheric mineral dust-derived nanoparticles with natural seawater-EPS and sunlight-mediated changes. Sci. Tot. Environ. 468-469, 265271. doi: 10.1016/j.scitotenv.2013.08.059

Keller, A. A., Wang, H., Zhou, D., Lenihan, H. S., Cherr, G., Cardinale, B. J., et al. (2010). Stability and aggregation of metal oxide nanoparticles in natural aqueous matrices. Environ. Sci. Technol. 44, 1962-1967. doi: 10.1021/es902987d doi: $10.1021 /$ es $902987 \mathrm{~d}$

Koelmans, A. A. (2019). Proxies for nanoplastic. Nat. Nanotechnol. 14, 307-308. doi: 10.1038/s41565-019-0416-z

Kokkinopoulou, M., Simon, J., Landfester, K., Mailänder, V., and Lieberwirth, I. (2017). Visualization of the protein corona: towards a biomolecular understanding of nanoparticle-cell-interactions. Nanoscale 9, 8858-8870. doi: $10.1039 / \mathrm{c} 7 \mathrm{nr} 02977 \mathrm{~b}$

Kuo, Y. Y., Zhang, H., Gerecke, A. C., and Wang, J. (2014). Chemical composition of nanoparticles released from thermal cutting of polystyrene foams and the associated isomerization of hexabromocyclododecane (HBCD) diastereomers. Aerosol. Air Qual. Res. 14, 1114-1120. doi: 10.4209/aaqr.2013.02.0059

Labille, J., Feng, J., Botta, C., Bornschneck, D., Sammut, M., Cabie, M., et al. (2010). Aging of $\mathrm{TiO} 2$ nanocomposites used in sunscreen. Dispersion and fate of the degradation products in aqueous environment. Environ. Poll. 158, 3482-3489. doi: $10.1016 /$ j.envpol.2010.02.012

Labille, J., Slomberg, D., Catalano, R., Robert, S., Apers-Tremelo, M., Boudenne, J., et al. (2020). Assessing UV filter inputs into beach waters during recreational activity: A field study of three French Mediterranean beaches from consumer survey to water analysis. Sci Tot. Environ. 76:136010. doi: 10.1016/j.scitotenv. 2019.136010

Lambert, S., Sinclair, C. J., Bradley, E. L., and Boxall, B. A. (2013). Effects of environmental conditions on latex degradation in aquatic systems. Sci Tot. Environ. 447, 225-234. doi: 10.1016/j.scitotenv.2012.12.067

Lambert, S., and Wagner, M. (2016). Formation of microscopic particles during the degradation of different polymers. Chemosphere 161, 510-517. doi: 10.1016/j. chemosphere.2016.07.042

Lara, S., Alnasser, F., Polo, E., Garry, D., Cristina, M., Giudice, L., et al. (2017). Identification of receptor binding to the biomolecular corona of nanoparticles. ACS Nano 11, 1884-1893. doi: 10.1021/acsnano.6b07933

Lebreton, L., and Andrady, A. (2019). Future scenarios of global plastic waste generation and disposal. Palgrave Commun. 5:6. doi: 10.1057/s41599-018$0212-7$

Lee, K. W., Shim, W. J., Kwon, O. Y., and Kang, J. H. (2013). Size-dependent effects of micro polystyrene particles in the marine copepod Tigriopus japonicus. Environ. Sci. Technol. 47, 11278-11283. doi: 10.1021/es401932b

Lehner, R., Weder, C., Petri-Fink, A., and Rothen-Rutishauser, B. (2019). Emergence of nanoplastic in the environment and possible impact on human health. Environ. Sci. Technol. 53, 1748-1765. doi: 10.1021/acs.est.8b05512

Lenz, R., Enders, K., and Nielsen, T. G. (2016). Microplastic exposure studies should be environmentally realistic. Proc. Natl. Acad. Sci U.S.A. 113, E4121E4122. doi: $10.1073 /$ pnas. 1606615113

Leslie, H. A. (2014). IVM Institute for Environmental Studies Review of Microplastics in Cosmetics. Environmental Chemistry and Toxicology AIMMS, VU University Amsterdam, Amsterdam.

Li, F., Liang, Z., Zheng, X., Zhao, W., Wu, M., and Wang, Z. (2015). Toxicity of nano-TiO2 on algae and the site of reactive oxygen species production. Aquat. Toxicol. 158, 1-13. doi: 10.1016/j.aquatox.2014.10.014

Libralato, G., Minetto, D., Totaro, S., Mičetić, I., Pigozzo, A., Sabbioni, E., et al. (2013). Embryotoxicity of $\mathrm{TiO} 2$ nanoparticles to Mytilus galloprovincialis (Lmk). Mar. Environ. Res. 92, 71-78. doi: 10.1016/j.marenvres.2013.08.015
Liu, Y., Li, W., Lao, F., Liu, Y., Wang, L., Bai, R., et al. (2011). Intracellular dynamics of cationic and anionic polystyrene nanoparticles without direct interaction with mitotic spindle and chromosomes. Biomaterials 32, 8291-8303. doi: 10.1016/j.biomaterials.2011.07.037

Long, R. A., and Azam, F. (1996). Abundant protein-containing particles in the sea. Science 10, 213-221. doi: 10.3354/ame010213

Loos, C., Syrovets, T., Musyanovych, A., Mailänder, V., Landfester, K., Ulrich Nienhaus, G., et al. (2014). Functionalized polystyrene nanoparticles as a platform for studying bio-nano interactions. Beilstein J. Nanotechnol. 5, $2403-$ 2412. doi: 10.3762/bjnano.5.250

Louie, S. M., Spielman-Sun, E. R., Small, M. J., Tilton, R. D., and Lowry, G. V. (2015). Correlation of the physicochemical properties of natural organic matter samples from different sources to their effects on gold nanoparticle aggregation in monovalent electrolyte. Environ. Sci. Technol. 49, 2188-2198. doi: 10.1021/ es505003d

Lowry, G. V., Gregory, K. B., Apte, S. C., and Lead, J. R. (2012). Transformations of nanomaterials in the environment. Environ. Sci. Technol. 46, 6893-6899. doi: $10.1021 / \mathrm{es} 300839 \mathrm{e}$

Lundqvist, M., Augustsson, C., Lilja, M., Lundkvist, K., Dahlbäck, B., Linse, S., et al. (2017). The nanoparticle protein corona formed in human blood or human blood fractions. PLoS One 12:0175871. doi: 10.1371/journal.pone.0175871

Lundqvist, M., Stigler, J., Elia, G., Lynch, I., Cedervall, T., and Dawson, K. A. (2008). Nanoparticle size and surface properties determine the protein corona with possible implications for biological impacts. Proc. Natl. Acad. Sci. U.S.A. 105, 14265-14270. doi: 10.1073/pnas.0805135105

Luo, M., Huang, Y., Zhu, M., Tang, Y., Ren, T., Ren, J., et al. (2018). Properties of different natural organic matter influence the adsorption and aggregation behavior of TiO2 nanoparticles. J. Saudi Chem. Soc. 22, 146-154. doi: 10.1016/j. jscs.2016.01.007

Lynch, I., Dawson, K. A., Lead, J. R., and Valsami-Jones, E. (2014). Macromolecular Coronas and Their Importance in Nanotoxicology and Nanoecotoxicology, 1st Edn, Amsterdam: Elsevier Ltd.

Mahmoudi, M., Abdelmonem, A. M., Behzadi, S., Clement, J. H., Dutz, S., Ejtehadi, M. R., et al. (2013). Temperature: the "ignored" factor at the nanobio interface. ACS Nano 7, 6555-6562. doi: 10.1021/nn305337c

Manfra, L., Rotini, A., Bergami, E., Grassi, G., Faleri, C., and Corsi, I. (2017). Ecotoxicology and environmental safety comparative ecotoxicity of polystyrene nanoparticles in natural seawater and reconstituted seawater using the rotifer Brachionus plicatilis. Ecotoxicol. Environ. Saf. 145, 557-563. doi: 10.1016/j. ecoenv.2017.07.068

Mari, X., Passow, U., Migon, C., Burd, A. B., and Legendre, L. (2017). Transparent exopolymer particles: effects on carbon cycling in the ocean. Prog. Oceanogr. 151, 13-37. doi: 10.1016/j.pocean.2016.11.002

Marisa, I., Marin, M. G., Caicci, F., Franceschinis, E., Martucci, A., and Matozzo, V. (2015). In vitro exposure of haemocytes of the clam Ruditapes philippinarum to titanium dioxide ( $\mathrm{TiO} 2)$ nanoparticles: nanoparticle characterization, effects on phagocytic activity and internalization of nanoparticles into haemocytes. Mar. Environ. Res. 103, 11-17. doi: 10.1016/j.marenvres.2014.11.002

Marques-Santos, L. F., Grassi, G., Bergami, E., Faleri, C., Balbi, T., Salis, A., et al. (2018). Cationic polystyrene nanoparticle and the sea urchin immune system: biocorona formation, cell toxicity, and multixenobiotic resistance phenotype. Nanotoxicology 12, 847-867. doi: 10.1080/17435390.2018.1482378

Matranga, V., and Corsi, I. (2012). Toxic effects of engineered nanoparticles in the marine environment: model organisms and molecular approaches. Mar. Environ. Res. 76, 32-40. doi: 10.1016/j.marenvres.2012.01.006

Matranga, V., Pinsino, A., Celi, M., Natoli, A., Bonaventura, R., Schröder, H. C., et al. (2005). Monitoring chemical and physical stress using sea urchin immune cells. Echinodermata 39, 85-110. doi: 10.1007/3-540-27683-1_5

Merdas, I., Thominette, F., and Verdu, J. (2003). Hydrolytic ageing of polyamide 11-Effect of carbon dioxide on polyamide 11 hydrolysis. Polym. Degrad. Stab. 79, 419-425. doi: 10.1016/s0141-3910(02)00358-0

Milani, S., Baldelli Bombelli, F., Pitek, A. S., Dawson, K. A., and Rädler, J. (2012). Reversible versus irreversible binding of transferrin to polystyrene nanoparticles: soft and hard corona. ACS Nano 6, 2532-2541. doi: 10.1021/ nn204951s

Miller, R. J., Bennett, S., Keller, A. A., Pease, S., and Lenihan, H. S. (2012). TiO2 nanoparticles are phototoxic to marine phytoplankton. PLoS One 7:30321. doi: 10.1371/journal.pone.0030321 
Miller, R. J., Lenihan, H. S., Muller, E. B., Tseng, N., Hanna, S. K., and Keller, A. A. (2010). Impacts of metal oxide nanoparticles on marine phytoplankton. Environ. Sci. Technol. 44, 7329-7334. doi: 10.1021/es100247x

Minetto, D., Ghirardini, A. V., and Libralato, G. (2016). Saltwater ecotoxicology of $\mathrm{Ag}, \mathrm{Au}, \mathrm{CuO}, \mathrm{TiO} 2, \mathrm{ZnO}$ and $\mathrm{C} 60$ engineered nanoparticles: an overview. Environ. Int 92-93, 189-201. doi: 10.1016/j.envint.2016.03.041

Minetto, D., Libralato, G., and Ghirardini, A. V. (2014). Ecotoxicity of engineered $\mathrm{TiO} 2$ nanoparticles to saltwater organisms: an overview. Environ. Int. 66, 18-27. doi: 10.1016/j.envint.2014.01.012

Minetto, D., Libralato, G., Marcomini, A., and Volpi Ghirardini, A. (2017). Potential effects of TiO2 nanoparticles and TiCl4 in saltwater to Phaeodactylum tricornutum and Artemia franciscana. Sci. Total Environ. 579, 1379-1386. doi: 10.1016/j.scitotenv.2016.11.135

Mishra, P., Vinayagam, S., Duraisamy, K., Patil, S. R., Godbole, J., Mohan, A., et al. (2019). Distinctive impact of polystyrene nano-spherules as an emergent pollutant toward the environment. Environ. Sci. Pollut. Res. 26, 1537-1547. doi: 10.1007/s11356-018-3698-z

Mitrano, D. M., Beltzung, A., Frehland, S., Schmiedgruber, M., Cingolani, A., and Schmidt, F. (2019). Synthesis of metal-doped nanoplastics and their utility to investigate fate and behaviour in complex environmental systems. Nat. Nanotechnol. 14, 362-368. doi: 10.1038/s41565-018-0360-3

Mitrano, D. M., Motellier, S., Clavaguera, S., and Nowack, B. (2015). Review of nanomaterial aging and transformations through the life cycle of nano-enhanced products. Environ. Int. 77, 132-147. doi: 10.1016/j.envint.2015. 01.013

Mohr, K., Sommer, M., Baier, G., Schöttler, S., Okwieka, P., Tenzer, S., et al. (2014). Aggregation behavior of polystyrene-nanoparticles in human blood serum and its impact on the in vivo distribution in mice. J. Nanomedicine Nanotechnol. 5:193. doi: 10.4172/2157-7439.1000193

Monopoli, M. P., Pitek, A. S., Lynch, I., and Dawson, K. A. (2013). Formation and characterization of the nanoparticle-protein corona. Methods Mol. Biol. 1025, 137-155. doi: 10.1007/978-1-62703-462-3_11

Monopoli, M. P., Walczyk, D., Campbell, A., Elia, G., Lynch, I., Baldelli Bombelli, F., et al. (2011). Physical-chemical aspects of protein corona: relevance to in vitro and in vivo biological impacts of nanoparticles. J. Am. Chem. Soc. 133, 2525-2534. doi: 10.1021/ja107583h

Mopper, K., Stubbins, A., Ritchie, J. D., Bialk, H. M., and Hatcher, P. G. (2007). Advanced instrumental approaches for characterization of marine dissolved organic matter: extraction techniques, mass spectrometry, and nuclear magnetic resonance spectroscopy. Chem. Rev. 107, 419-442. doi: 10. $1021 / \mathrm{cr} 050359 \mathrm{~b}$

Morelli, E., Gabellieri, E., Bonomini, A., Tognotti, D., Grassi, G., and Corsi, I. (2018). TiO2 nanoparticles in seawater: aggregation and interactions with the green alga Dunaliella tertiolecta. Ecotoxicol. Environ. Saf. 148, 184-193. doi: 10.1016/j.ecoenv.2017.10.024

Mourdikoudis, S., Pallares, R. M., and Thanh, N. T. K. (2018). Characterization techniques for nanoparticles: comparison and complementarity upon studying nanoparticle properties. Nanoscale 10, 12871-12934. doi: 10.1039/c8nr02278j

Mwaanga, P., Carraway, E. R., and Schlautman, M. A. (2014). Preferential sorption of some natural organic matter fractions to titanium dioxide nanoparticles: influence of $\mathrm{pH}$ and ionic strength. Environ. Monit. Assess. 186, 8833-8844. doi: 10.1007/s10661-014-4047-4

Nason, J. A., McDowell, S. A., and Callahan, T. W. (2012). Effects of natural organic matter type and concentration on the aggregation of citrate-stabilized gold nanoparticles. J. Environ. Monit. 14, 1885-1892. doi: 10.1039/c2em00005a

Nel, A., Xia, T., Madler, L., and Li, N. (2006). Toxic potential of materials at the nanolevel. Science 311:622. doi: 10.1126/science.1114397

Nigro, M., Berbardeschi, M., Costagliola, D., Della Torre, C., Frenzilli, G., Guidi, P., et al. (2015). n- $\mathrm{TiO}_{2}$ and $\mathrm{CdCl}_{2}$ co-exposure to titanium dioxide nanoparticles and cadmium: genomic, DNA and chromosomal damage evaluation in the marine fish European sea bass Dicentrarchus labrax. Aquat. Toxicol. 168, 72-77. doi: 10.1016/j.aquatox.2015.09.013

Nogueira, V., Lopes, I., Rocha-Santos, T. A. P., Rasteiro, M. G., Abrantes, N., Gonçalves, F., et al. (2015). Assessing the ecotoxicity of metal nano-oxides with potential for wastewater treatment. Environ. Sci. Pollut. Res 22, 13212-13224. doi: 10.1007/s11356-015-4581-9

Noventa, S., Rowe, D., and Galloway, T. (2018). Mitigating effect of organic matter on the in vivo toxicity of metal oxide nanoparticles in the marine environment. Environ. Sci. Nano. 5, 1764-1777. doi: 10.1039/c8en00175h
Nowack, B., and Mitrano, D. M. (2018). Procedures for the production and use of synthetically aged and product released nanomaterials for further environmental and ecotoxicity testing. Nanoimpact 10, 70-80. doi: 10.1016/j. impact.2017.12.001

OECD 201 (2011). Test No. 201: Freshwater Alga and Cyanobacteria, Growth Inhibition Test, OECD Guidelines for the Testing of Chemicals, Section 2. Paris: OECD Publishing, doi: 10.1787/9789264069923-en

Oren, A. (2005). A hundred years of dunaliella research: 1905-2005. Saline Syst. 1:2. doi: 10.1186/1746-1448-1-2

Ortega-Morales, B. O., Santiago-García, J. L., Chan-Bacab, M. J., Moppert, X., Miranda-Tello, E., Fardeau, M. L., et al. (2007). Characterization of extracellular polymers synthesized by tropical intertidal biofilm bacteria. J. Appl. Microbiol. 102, 254-264. doi: 10.1111/j.1365-2672.2006.03085.x

Passow, U. (2002). Transparent exopolymer particles (TEP) in aquatic environments. Prog. Oceanogr. 55, 287-333. doi: 10.1016/S0079-6611(02) 00138-6

Paterson, G., Ataria, J. M., Hoque, E., and Metcalfe, C. D. (2011). The toxicity of titanium dioxide nanopowder to early life stages of the Japanese medaka (Oryzias latipes). Chemosphere 82, 1002-1009. doi: 10.1016/j.chemosphere. 2010.10.068

Pellegrino, F., Pellutiè, L., Sordello, F., Minero, C., Ortel, H., Hodoroaba, V., et al. (2017). Influence of agglomeration and aggregation on the photocatalytic activity of TiO2 nanoparticles. Appl. Catal. B Environ. 216, 80-87. doi: 10.1016/ j.apcatb.2017.05.046

Petersen, E. J., Diamond, S. A., Kennedy, A. J., Goss, G. G., Lead, J., Hanna, S. K., et al. (2015). Adapting OECD aquatic toxicity tests for use with manufactured nanomaterials: key issues and consensus recommendations. Environ. Sci. Technol. 49, 9532-9547. doi: 10.1021/acs.est.5b00997

Petosa, A. R., Jaisi, D. P., Quevedo, I. R., Elimelech, M., and Tufenkji, N. (2010). Aggregation and deposition of engineered nanomaterials in aquatic environments: role of physicochemical interactions. Environ. Sci. Technol. 44, 6532-6549. doi: 10.1021/es100598h

Piella, J., Bastús, N. G., and Puntes, V. (2017). Size-dependent protein-nanoparticle interactions in citrate-stabilized gold nanoparticles: the emergence of the protein corona. Bioconjug. Chem. 28, 88-97. doi: 10.1021/acs.bioconjchem. $6 \mathrm{~b} 00575$

Pinsino, A., Bergami, E., Della Torre, C., Vannuccini, M. L., Addis, P., Secci, M., et al. (2017). Amino-modified polystyrene nanoparticles affect signalling pathways of the sea urchin (Paracentrotus lividus) embryos. Nanotoxicology 11:360. doi: 10.1080/17435390.2017.1279360

Pinsino, A., and Matranga, V. (2015). Sea urchin immune cells as sentinels of environmental stress. Dev. Comp. Immunol. 49, 198-205. doi: 10.1016/j.dci. 2014.11.013

Pinsino, A., Russo, R., Bonaventura, R., Brunelli, A., Marcomini, A., and Matranga, V. (2015). Titanium dioxide nanoparticles stimulate sea urchin immune cell phagocytic activity involving signalling pathway. Sci. Rep. 5, 1-12. doi: 10.1038/ srep 14492

Praetorius, A., Badetti, E., Brunelli, A., Clavier, A., Gallego-Urrea, J. A., Gondikas, A., et al. (2020). Strategies for determining heteroaggregation attachment efficiencies of engineered nanoparticles in aquatic environments. Environ. Sci. Nano. 7, 351-367. doi: 10.1039/c9en01016e

Praetorius, A., Labille, J., Scheringer, M., Thill, A., Hungerbuhler, K., and Bottero, J. Y. (2014). Heteroaggregation of titanium dioxide nanoparticles with model natural colloids under environmentally relevant conditions. Environ. Sci. Technol. 48, 10690-10698. doi: 10.1021/es501655v

Ren, C., Hu, X., and Zhou, Q. (2016). Influence of environmental factors on nanotoxicity and knowledge gaps thereof. Nanoimpact 2, 82-92. doi: 10.1016/j. impact.2016.07.002

Renner, G., Schmidt, T. C., and Schram, J. (2018). Analytical methodologies for monitoring micro(nano)plastics: which are fit for purposes? Curr. Opin. Environ. Sci. Health 1, 55-61. doi: 10.1016/j.coesh.2017.11.001

Ribeiro, A. R., Leite, P. E., Falagan-Lotsch, P., Benetti, F., Micheletti, C., Budtz, H. C., et al. (2017). Challenges on the toxicological predictions of engineered nanoparticles. Nanoimpact 8, 59-72. doi: 10.1016/j.impact.2017.07.006

Ritz, S., Schöttler, S., Kotman, N., Baier, G., Musyanovych, A., Kuharev, J., et al. (2015). Protein corona of nanoparticles: distinct proteins regulate the cellular uptake. Biomacromolecules 16, 1311-1321. doi: 10.1021/acs.biomac.5b00108

Robichaud, C. O., Uyar, A. E., Darby, M. R., Zucker, L. G., and Wiesner, M. R. (2009). Estimates of upper bounds and trends in nano-TiO2 production as 
a basis for exposure assessment. Environ. Sci. Technol. 43, 4227-4233. doi: $10.1021 /$ es8032549

Rocco, L., Santonastasio, M., Nigro, M., Mottola, F., Costagliela, D., Bernardeschi, M., et al. (2015). Genomic and chromosomal damage in the marine mussel Mytilus galloprovincialis: effects of the combined exposure titanium dioxide nanoparticles and cadmium chloride. Mar. Environ. Res. 111, 144-148. doi: 10.1016/j.marenvres.2015.09.004

Romanello, M. B., and Fidalgo de Cortalezzi, M. M. (2013). An experimental study on the aggregation of $\mathrm{TiO} 2$ nanoparticles under environmentally relevant conditions. Water Res. 47, 3887-3898. doi: 10.1016/j.watres.2012. 11.061

Salvati, A., Åberg, C., dos Santos, T., Varela, J., Pinto, P., Lynch, I., et al. (2011). Experimental and theoretical comparison of intracellular import of polymeric nanoparticles and small molecules: toward models of uptake kinetics. Nanomed. Nanotechnol. Biol. Med. 7, 818-826. doi: 10.1016/j.nano.2011. 03.005

Sayes, C. M., Wahi, R., Kurian, P. A., Liu, Y., West, J. L., Ausman, K. D., et al. (2006). Correlating nanoscale titania structure with toxicity: a cytotoxicity and inflammatory response study with human dermal fibroblasts and human lung epithelial cells. Toxicol. Sci. 92, 174-185. doi: 10.1093/toxsci/kfj197

Schirinzi, G. F., Llorca, M., Seró, R., Moyano, E., Barceló, D., Abad, E., et al. (2019). Trace analysis of polystyrene microplastics in natural waters. Chemosphere 236:52. doi: 10.1016/j.chemosphere.2019.07.052

Schwaferts, C., Niessner, R., Elsner, M., and Ivleva, N. P. (2019). Methods for the analysis of submicrometer- and nanoplastic particles in the environment. Trend Anal. Chem. 112, 52-65. doi: 10.1016/j.trac.2018.12.014

Sendra, M., Moreno-Garrido, I., Yeste, M. P., Gatica, J. M., and Blasco, J. (2017a). Toxicity of $\mathrm{TiO} 2$, in nanoparticle or bulk form to freshwater and marine microalgae under visible light and UV-A radiation. Environ. Pollut. 227, 39-48. doi: 10.1016/j.envpol.2017.04.053

Sendra, M., Sánchez-Quiles, D., Blasco, J., Moreno-Garrido, I., Lubián, L. M., Pérez-García, S., et al. (2017b). Effects of $\mathrm{TiO} 2$ nanoparticles and sunscreens on coastal marine microalgae: ultraviolet radiation is key variable for toxicity assessment. Environ. Int. 98, 62-68. doi: 10.1016/j.envint.2016.09.024

Sendra, M., Saco, A., Yeste, M. P., Romero, A., Novoa, B., and Figueras, A. (2019a). Nanoplastics: from tissue accumulation to cell translocation into Mytilus galloprovincialis hemocytes. resilience of immune cells exposed to nanoplastics and nanoplastics plus Vibrio splendidus combination. J. Hazard. Mater. 388:121788. doi: 10.1016/j.jhazmat.2019.121788

Sendra, M., Staf, E., Pilar, M., and Moreno-garrido, I. (2019b). Are the primary characteristics of polystyrene nanoplastics responsible for toxicity and ad / absorption in the marine diatom Phaeodactylum tricornutum? Trend Anal. Chem. 249, 610-619. doi: 10.1016/j.envpol.2019.03.047

Sendra, M., Volland, M., Balbi, T., Fabbri, R., Yeste, M. P., Gatica, J. M., et al. (2018). Cytotoxicity of $\mathrm{CeO} 2$ nanoparticles using in vitro assay with Mytilus galloprovincialis hemocytes: relevance of zeta potential, shape and biocorona formation. Aquat. Toxicol. 200, 13-20. doi: 10.1016/j.aquatox.2018. 04.011

Seoane, M., González-Fernández, C., Soudant, P., Huvet, A., Esperanza, M., Cid, A., et al. (2019). Polystyrene microbeads modulate the energy metabolism of the marine diatom Chaetoceros neogracile. Environ. Pollut. 251, 363-371. doi: 10.1016/j.envpol.2019.04.142

Shang, L., and Nienhaus, G. U. (2017). In situ characterization of protein adsorption onto nanoparticles by fluorescence correlation spectroscopy. Acc. Chem. Res. 50, 387-395. doi: 10.1021/acs.accounts.6b00579

Shi, W., Han, Y., Guo, C., Su, W., Zhao, X., Zha, S., et al. (2019). Ocean acidification increases the accumulation of titanium dioxide nanoparticles (nTiO 2) in edible bivalve mollusks and poses a potential threat to seafood safety. Sci. Rep. 9, 1-10. doi: 10.1038/s41598-019-40047-1

Shi, W., Han, Y., Guo, C., Zhao, X., Liu, S., Su, W., et al. (2017). Immunotoxicity of nanoparticle $\mathrm{nTiO} 2$ to a commercial marine bivalve species, Tegillarca granosa. Fish. Shellf. Immun. 66, 300-306. doi: 10.1016/j.fsi.2017. 05.036

Shiu, R.-F., Vazquez, C. I., Tsai, Y.-Y., Torres, G. V., Chen, C.-S., Santschi, P. H., et al. (2019). Nano-plastics induce aquatic particulate organic matter (microgels) formation. Sci. Total Environ. 706:135681. doi: 10.1016/j.scitotenv. 2019.135681
Sillanpää, M., Paunu, T.-M., and Sainio, P. (2011). Aggregation and deposition of engineered $\mathrm{TiO} 2$ nanoparticles in natural fresh and brackish waters. J. Phys. Conf. Ser. 304, 1-8. doi: 10.1088/1742-6596/304/1/012018

Silvestre, C., Duraccio, D., and Cimmino, S. (2011). Food packaging based on polymer nanomaterials. Prog. Polym. Sci. 36, 1766-1782. doi: 10.1016/j. progpolymsci.2011.02.003

Singh, N., Tiwari, E., Khandelwal, N., and Darbha, G. K. (2019). Understanding the stability of nanoplastics in aqueous environments: effect of ionic strength, temperature, dissolved organic matter, clay, and heavy metals. Environ. Sci. Nano 6, 2968-2976. doi: 10.1039/c9en00557a

Sjollema, S. B., Redondo-hasselerharm, P., Leslie, H. A., Kraak, M. H. S., and Vethaak, A. D. (2016). Do plastic particles affect microalgal photosynthesis and growth? Aquat. Toxicol. 170, 259-261. doi: 10.1016/j.aquatox.2015.12.002

Snell, T. W., and Hicks, D. G. (2009). Assessing toxicity of nanoparticles using Brachionus manjavacas (Rotifera). Environ. Toxicol. 26, 146-152. doi: $10.1002 /$ tox

Sun, J., Guo, L., Zhang, H., and Zhao, L. (2014). UV irradiation induced transformation of $\mathrm{TiO} 2$ nanoparticles in water: aggregation and photoreactivity. Environ. Sci. Technol. 48, 11962-11968. doi: 10.1021/es502 $360 \mathrm{c}$

Sun, T. Y., Bornhöft, N. A., Hungerbühler, K., and Nowack, B. (2016). Dynamic probabilistic modeling of environmental emissions of engineered nanomaterials. Environ. Sci. Technol. 50, 4701-4711. doi: 10.1021/acs.est. 5 b05828

Sun, T. Y., Gottschalk, F., Hungerbuhler, K., and Nowack, B. (2014). Comprehensive probabilistic modelling of environmental emissions of engineered nanomaterials. Environ. Pollut. 185, 69-76. doi: 10.1016/j.envpol. 2013.10.004

Surette, M. C., and Nason, J. A. (2016). Effects of surface coating character and interactions with natural organic matter on the colloidal stability of gold nanoparticles. Environ. Sci. Nano 3, 1144-1152. doi: 10.1039/C6EN00180G

Surette, M. C., and Nason, J. A. (2019). Nanoparticle aggregation in a freshwater river: the role of engineered surface coatings. Environ. Sci. Nano 6, 540-553. doi: $10.1039 /$ C8EN01021H

Tallec, K., Huvet, A., Di, C., Gonz, C., Lambert, C., Petton, B., et al. (2018). Nanoplastics impaired oyster free living stages, gametes and embryos. Environ. Pollut. 242, 1226-1235. doi: 10.1016/j.envpol.2018.08.020

Tenzer, S., Docter, D., Kuharev, J., Musyanovych, A., Fetz, V., Hecht, R., et al. (2013). Rapid formation of plasma protein corona critically affects nanoparticle pathophysiology. Nat. Nanotechnol. 8, 772-781. doi: 10.1038/nnano.2013.181

Tenzer, S., Docter, D., Rosfa, S., Wlodarski, A., Kuharev, J., Rekik, A., et al. (2011). Nanoparticle size is a critical physicochemical determinant of the human blood plasma corona: a comprehensive quantitative proteomic analysis. ACS Nano 5 , 7155-7167. doi: 10.1021/nn201950e

Ter Halle, A., Jeanneau, L., Martignac, M., Jardé, E., Pedrono, B., Brach, L., et al. (2017). Nanoplastic in the North Atlantic subtropical gyre. Environ. Sci. Technol. 51, 13689-13697. doi: 10.1021/acs.est.7b03667

Therezien, M., Thill, A., and Wiesner, M. R. (2014). Importance of heterogeneous aggregation for NP fate in natural and engineered systems. Sci. Total. Environ. 48, 309-318. doi: 10.1016/j.scitotenv.2014.03.020

Tian, S., Zhang, Y., Song, C., Zhu, X., and Xing, B. (2014). Titanium dioxide nanoparticles as carrier facilitate bioaccumulation of phenanthrene in marine bivalve, ark shell (Scapharca subcrenata). Environ. Pollut. 192, 59-64. doi: 10. 1016/j.envpol.2014.05.010

Tian, S., Zhang, Y., Song, C., Zhu, X., and Xing, B. (2015). Bioaccumulation and biotransformation of polybrominated diphenyl ethers in the marine bivalve (Scapharca subcrenata): influence of titanium dioxide nanoparticles. Mar. Poll. Bull. 90, 48-53. doi: 10.1016/j.marpolbul.2014.11.031

Tovar-Sánchez, A., Sánchez-Quiles, D., Basterretxea, G., Benedé, J. L., Chisvert, A., Salvador, A., et al. (2013). Sunscreen products as emerging pollutants to coastal waters. PLoS One 8:e65451. doi: 10.1371/journal.pone

Uchino, T., Tokunaga, H., Ando, M., and Utsumi, H. (2002). Quantitative determination of $\mathrm{OH}$ radical generation and its cytotoxicity induced by $\mathrm{TiO} 2-$ UVA treatment. Toxicol. In Vitro 16, 629-635. doi: 10.1016/s0887-2333(02) 00041-3

Vance, M. E., Kuiken, T., Vejerano, E. P., McGinnis, S. P., and Hochella, M. F. (2015). Nanotechnology in the real world: redeveloping the nanomaterial 
consumer products inventory. Beilstein J. Nanotechnol. 6, 1769-1780. doi: 10. 3762/bjnano.6.181

Vannuccini, M. L., Grassi, G., Leaver, M. J., and Corsi, I. (2015). Combination effects of nano-TiO2 and 2,3,7,8-tetrachlorodibenzo-p-dioxin (TCDD) on biotransformation gene expression in the liver of European sea bass Dicentrarchus labrax. Comp. Biochem. Physiol. Part C 17, 71-78. doi: 10.1016/j. cbpc.2015.07.009

Varó, I., Perini, A., Torreblanca, A., Garcia, Y., Bergami, E., Vannuccini, M. L., et al. (2019). Time-dependent effects of polystyrene nanoparticles in brine shrimp Artemia franciscana at physiological, biochemical and molecular levels. Sci. Total Environ. 675:157. doi: 10.1016/j.scitotenv.2019.04.157

Velev, O. D., and Kaler, E. W. (1999). In situ assembly of colloidal particles into miniaturized biosensors. Langmuir 15, 3693-3698. doi: 10.1021/la981729c

Venâncio, C., Ferreira, I., Martins, M. A., Soares, A. M. V. M., Lopes, I., and Oliveira, M. (2019). The effects of nanoplastics on marine plankton: a case study with polymethylmethacrylate. Ecotoxicol. Environ. Saf. 184:109632. doi: 10.1016/j.ecoenv.2019.109632

Verdugo, P., Alldredge, A. L., Azam, F., Kirchman, D. L., Passow, U., and Santschi, P. H. (2004). The oceanic gel phase: a bridge in the DOM-POM continuum. Mar. Chem. 92, 67-85. doi: 10.1016/j.marchem.2004.06.017

Verma, A., and Stellacci, F. (2010). Effect of surface properties on nanoparticle-cell interactions. Small 6, 12-21. doi: 10.1002/smll.200901158

Vignardi, C. P., Hasue, F. M., Sartório, P. V., Cardoso, C. M., and Machado, A. S. (2015). Genotoxicity, potential cytotoxicity and cell uptake of titanium dioxide nanoparticles in the marine fish Trachinotus carolinus (Linnaeus, 1766). Aquat. Toxicol. 158, 218-229. doi: 10.1016/j.aquatox.2014.11.008

von der Kammer, F., Ferguson, P. L., Holden, P. A., Masion, A., Rogers, K. R., Klaine, S. J., et al. (2012). Analysis of engineered nanomaterials in complex matrices (environment and biota): general considerations and conceptual case studies. Environ. Toxicol. Chem. 31, 32-49. doi: 10.1002/etc.723

Vroman, L. (1962). Effect of adsorbed proteins on the wettability of hydrophilic and hydrophobic solids. Nature 196, 476-477. doi: 10.1038/196476a0

Walkey, C. D., Olsen, J. B., Guo, H., Emili, A., and Chan, W. C. W. (2012). Nanoparticle size and surface chemistry determine serum protein adsorption and macrophage uptake. J. Am. Chem. Soc. 134, 2139-2147. doi: 10.1021/ ja2084338

Walsh, R. B., Nelson, A., Skinner, W. M., Parsons, D., and Craig, V. S. J. (2012). Direct measurement of Van der Waals and diffuse double-layer forces between titanium dioxide surfaces produced by atomic layer deposition. J. Phys. Chem. C 116, 7838-7847. doi: 10.1021/jp300533m

Wan, S., Kelly, P. M., Mahon, E., Stöckmann, H., Rudd, P. M., Caruso, F., et al. (2015). The "sweet" Side of the protein corona: effects of glycosylation on nanoparticle-cell interactions. ACS Nano 9, 2157-2166. doi: 10.1021/ nn506060q

Wang, F., Bexiga, M. G., Anguissola, S., Boya, P., Simpson, J. C., Salvati, A., et al. (2013). Time resolved study of cell death mechanisms induced by aminemodified polystyrene nanoparticles. Nanoscale 5, 10868-10876. doi: 10.1039/ c3nr03249c

Wang, Y., Hu, M., Li, Q., Li, J., Lin, D., and Lu, W. (2014). Immune toxicity of $\mathrm{TiO}_{2}$ under hypoxia in the green-lipped mussel Perna viridis based on flow cytometric analysis of hemocyte parameters. Sci. Total Environ. 47, 791-799. doi: 10.1016/j.scitotenv.2013.09.060

Wang, Y., Zhu, X., Lao, Y., Lv, X., Tao, Y., Huang, B., et al. (2016). TiO2 nanoparticles in the marine environment: physical effects responsible for the toxicity on algae Phaeodactylum tricornutum. Sci. Total Environ. 565, 818-826. doi: 10.1016/j.scitotenv.2016.03.164

Wang, Z., Xia, B., Chen, B., Sun, X., Zhu, L., Zhao, J., et al. (2017). Trophic transfer of $\mathrm{TiO} 2$ nanoparticles from marine microalga (Nitzschia closterium) to scallop (Chlamys farreri) and related toxicity. Environ. Sci. Nano 4, 415-424. doi: 10.1039/C6EN00365F

Ward, J. E., and Kach, D. J. (2009). Marine aggregates facilitate ingestion of nanoparticles by suspension feeding bivalves. Mar. Environ. Res. 68, 137-142. doi: 10.1016/j.marenvres.2009.05.002

Wegner, A., Besseling, E., Foekema, E. M., Kamermans, P., and Koelmans, A. A. (2012). Effects of nanopolystyrene on the feeding behavior of the blue mussel
(Mytilus edulis L.). Environ. Toxicol. Chem. 31, 2490-2497. doi: 10.1002/etc. 1984

Wilkinson, K. J., and Lead, J. R. (2007). Environmental Colloids and Particles: Behaviour, Separation and Characterisation. Hoboken, NJ: John Wiley \& Sons.

Windler, L., Lorenz, C., von Goetz, N., Hungerbuhler, K., Amberg, M., Heuberger, M., et al. (2012). Release of titanium dioxide from textiles during washing. Environ. Sci. Technol. 46, 8181-8188. doi: 10.1021/es301633b

Winzen, S., Schoettler, S., Baier, G., Rosenauer, C., Mailaender, V., Landfester, K., et al. (2015). Complementary analysis of the hard and soft protein corona: sample preparation critically effects corona composition. Nanoscale 7, 29923001. doi: 10.1039/C4NR05982D

Wu, J., Jiang, R., Lin, W., and Ouyang, G. (2019). Effect of salinity and humic acid on the aggregation and toxicity of polystyrene nanoplastics with different functional groups and charges. Environ. Pollut. 245, 836-843. doi: 10.1016/j. envpol.2018.11.055

Wu, W., Giese, R. F., and Van Oss, C. J. (1999). Stability versus flocculation of particle suspensions in water-correlation with the extended DLVO approach for aqueous systems, compared with classical DLVO theory. Coll. Surf. B 14, 47-55. doi: 10.1016/S0927-7765(99)00023-5

Xia, B., Chen, B., Sun, X., Qu, K., Ma, F., and Du, M. (2015). Interaction of $\mathrm{TiO} 2$ nanoparticles with the marine microalga Nitzschia closterium: growth inhibition, oxidative stress and internalization. Sci. Total Environ. 508, 525-533. doi: 10.1016/j.scitotenv.2014.11.066

Yi, X., Wang, J., Li, Z., Zhang, Z., Chi, T., Guo, M., et al. (2019). The effect of polystyrene plastics on the toxicity of triphenyltin to the marine diatom Skeletonema costatum - influence of plastic particle size. Environ. Sci. Pollut. Res. Int. 26, 25445-25451. doi: 10.1007/s11356-019-05826-3

Yin, L., Liu, H., Cui, H., Chen, B., Li, L., and Wu, F. (2019). Impacts of polystyrene microplastics on the behavior and metabolism in a marine demersal teleost, black rockfish (Sebastes schlegelii). J. Hazard. Mater. 380:120861. doi: 10.1016/j. jhazmat.2019.120861

Yue, Y., Behra, R., Sigg, L., Fernández Freire, P., Pillai, S., and Schirmer, K. (2015). Toxicity of silver nanoparticles to a fish gill cell line: role of medium composition. Nanotoxicology 9, 54-63. doi: 10.3109/17435390.2014.88 9236

Yue, Y., Behra, R., Sigg, L., and Schirmer, K. (2016a). Silver nanoparticles inhibit fish gill cell proliferation in protein-free culture medium. Nanotoxicology 10, 1075-1083. doi: 10.3109/17435390.2016.1172677

Yue, Y., Behra, R., Sigg, L., Suter, M. J.-F., Pillai, S., and Schirmer, K. (2016b). Silver nanoparticle-protein interactions in intact rainbow trout gill cells. Environ. Sci. Nano 3, 1174-1185. doi: 10.1039/C6EN00119J

Zhang, H., Kuo, Y. Y., Gerecke, A. C., and Wang, J. (2012). Co-release of hexabromocyclododecane (HBCD) and nano- and microparticles from thermal cutting of polystyrene foams. Environ. Sci. Technol. 46, 10990-10996. doi: 10. 1021/es302559v

Zhu, L., Zhao, S., Bittar, T. B., and Stubbins, A. (2020). Photochemical dissolution of buoyant microplastics to dissolved organic carbon: rates and microbial impacts. J. Hazard. Mater. 383:121065. doi: 10.1016/j.jhazmat.2019. 121065

Zhu, X., Zhou, J., and Cai, Z. (2011). TiO2 nanoparticles in the marine environment: impact on the toxicity of tributyltin to abalone (Haliotis diversicolor supertexta) embryos. Environ. Sci. Technol. 45, 3753-3758. doi: $10.1021 / \mathrm{es} 103779 \mathrm{~h}$

Conflict of Interest: The authors declare that the research was conducted in the absence of any commercial or financial relationships that could be construed as a potential conflict of interest.

Copyright (c) 2020 Corsi, Bergami and Grassi. This is an open-access article distributed under the terms of the Creative Commons Attribution License (CC BY). The use, distribution or reproduction in other forums is permitted, provided the original author(s) and the copyright owner(s) are credited and that the original publication in this journal is cited, in accordance with accepted academic practice. No use, distribution or reproduction is permitted which does not comply with these terms. 